\title{
Rent Seeking and Bias in Appeals Systems*
}

\author{
Tim Friehe \\ University of Marburg \\ Ansgar Wohlschlegel \\ University of Portsmouth
}

June 19, 2018

\begin{abstract}
We analyze a litigation contest in which plaintiff and defendant seek to win in trial court, and the losing litigant may appeal. In our setup, the appeals court's judgment depends on the trial court's judgment, the merits of the litigants' arguments, and their efforts in the appeals stage. We find that the possibility of appeal increases the favorite's probability of winning as compared to that in a single-stage system, as the favorite has higher effort incentives in the first-instance authority than the underdog. Moreover, we show that the possibility of appeal may increase total rent-seeking efforts and make the case less likely to be tried, or that it surprisingly may have the opposite effects, and how the direction of these effects depends on the model parameters.
\end{abstract}

JEL Classification: D72; K41

Keywords: Appeals; Litigation; Justice; Contest; Effort.

${ }^{*}$ We would like to thank Florian Baumann, Philipp Denter, Michael Neugart, Claudia Landeo, Wolfgang Luhan, Paul Pecorino, Johannes Schneider, Elisabeth Schulte, and participants at the 2016 EALE conference in Bologna and at seminars in Constance and Portsmouth for helpful suggestions. Moreover, we are very thankful for the comments and suggestions received from an anonymous reviewer and the responsible editor, William Hubbard. Financial support by the British Academy / Leverhulme Trust Small Research Grant scheme is gratefully acknowledged. 


\section{Introduction}

A growing overload of judicial systems, surging litigation costs, and concerns about access to justice being restricted to litigants with deep pockets has sparked a debate on how to improve the efficiency and justice of the legal system. The right to and scope of appeal has been center stage in much of this discussion. For instance, the European Commission for the Efficiency of Justice (CEPEJ (2014)) specifically promotes the use of alternative dispute resolution to reduce courts' workload and improve access to justice, where some forms of these alternative procedures explicitly bar appeal. However, restricting the right to appeal involves a trade-off: While the possibility of appeal may tend to prolong cases, clog the legal system, and make litigation more expensive, it is accredited with correcting legal errors of lower-level courts (e.g., Shavell 1995, 2006). Moreover, it remains unclear whether the aforementioned supposition that the possibility of an appeal increases litigation costs carries over to the more realistic case in which the level of litigation spending is endogenously determined by litigants.

This paper seeks to improve our understanding of the impacts of the possibility to appeal. We study how the possibility of appeals bears on rent-seeking effort incentives, the relationship between case outcomes and the underlying merits of the case, and the incentives to bring a case. The analysis is set in the context of litigation, but the issues dealt with are important in other contexts as well ${ }^{1}$

In our analysis, we extend the standard model of a litigation contest in which the litigants struggle about a fixed judgment of common value by adding a second stage, the appeal stage, that will be reached only when litigants have incentives to appeal the trial court's judgment. At the trial stage, both the merits of the plaintiff's case and the parties' effort levels influence the court's judgment. Should the losing litigant file an appeal and the victorious litigant choose to defend her case, the appeals court's judgment will again

\footnotetext{
${ }^{1}$ People affected by the decisions of public bodies are usually protected by the right of appeal. For example, parents may appeal school allocation decisions. Moreover, private organizations often implement appeal systems to ensure that employees are treated fairly. In fact, allowing employees to appeal is part of codes of practice set by organizations such as ACAS in the UK (e.g., ACAS (2015)), and may involve resorting to external tribunals.
} 
depend on the merits of the case and the litigants' efforts at the appeals stage, but also on the trial court's judgment. This last effect is included in order to account for the fact that, in most jurisdictions, the extent to which a trial judgment can be overturned in an appeal is limited.

We find that the possibility of appeal increases the probability that the litigant with the relatively better case wins, compared to that in a single-stage system (i.e., it introduces a pro-favorite bias) ${ }^{2}$ The possibility of appeal induces the litigant with the better case to exert more trial effort than the other litigant. This asymmetry in effort incentives stems from asymmetric stakes in the court of first instance: The litigant with the better case anticipates that winning (losing) at trial will make the appeals contest more (less) asymmetric and, thus, less (more) contested, and vice versa for the underdog. This effect makes winning at trial more attractive for the litigant with the better case, and less attractive for the underdog. Hence, this asymmetry in rent-seeking incentives shifts the success probabilities away from those in a single-stage contest, in which equilibrium success probabilities are commensurate with the merits of the case (Hirshleifer and Osborne (2001)).

To see this intuition more formally, consider a simplified version of the contest success function that we will use in the analysis below. Let $p$ and $d$ be the plaintiff's and the defendant's litigation effort, respectively, measured in terms of their costs, and $Y$ a parameter that indicates the strength of the plaintiff's case, and let the plaintiff win in court with probability

$$
\pi(p, d, Y)=\frac{p Y}{p Y+d(1-Y)} .
$$

If both litigants' effort choices are identical, the plaintiff will win with probability $Y$. Denoting the plaintiff's and the defendant's contest stakes (i.e., the respective difference between the litigant's payoff from winning and losing in court) by $V_{P}$ and $V_{D}$, the plaintiff seeks to maximize $\pi(p, d, Y) V_{P}-p$ using effort $p$, and the defendant strives to maximize $(1-\pi(p, d, Y)) V_{D}-d$ using $d$. In equilibrium, litigation efforts amount to $p^{*}=Y(1-Y) V_{P}$

\footnotetext{
${ }^{2}$ Following the convention in the contest literature such as Dixit (1987), we call a litigant the favorite who would win in a one-stage contest with simultaneous moves with a probability greater than one half.
} 
and $d^{*}=Y(1-Y) V_{D}$. If the lawsuit is about determining liability for damages, each litigant's gain is just the other litigant's loss, so that $V_{P}=V_{D}$, and both litigants' equilibrium effort choices are identical independent of the strength of the plaintiff's case. Furthermore, equilibrium effort choices are maximum for $Y=1 / 2$. That is to say, the more contested the lawsuit is, the higher will be both litigants' effort levels and, as the size of the potential damages is constant, the lower will be their expected equilibrium payoffs.

While these insights are well-known from the literature on litigation contests (particularly Hirshleifer and Osborne (2001)), we extend this model by considering an appeals stage. In reality, a losing litigant's odds to overturn the trial judgment in the appeals court are worse than her ex-ante odds of winning at trial. We reflect this fact by assuming that, after winning (losing) at trial, the strength $Z$ of the plaintiff's case in the appeals court is above (below) the strength $Y$ that it had at trial. Both litigants' equilibrium effort levels are still identical at $Z(1-Z)$ times the damages, but they depend on who had won at trial. Suppose, for instance, that the plaintiff has a weak case $(Y<1 / 2)$. If the plaintiff has won at trial, $Z$ is larger than $Y$ and, therefore, the appeals contest more contested than if the plaintiff had lost at trial. As a consequence, both litigants' equilibrium payoffs in the appeals stage are lower after the plaintiff has won at trial than after she had lost at trial. Assuming for simplicity that all cases reach the appeals court, each litigant's stakes on the trial stage are given by the difference in the equilibrium appeals stage payoff after winning and losing at trial. For the plaintiff with a weak case in trial court, winning at trial means a more contested appeals stage and, therefore, high equilibrium effort costs, and vice versa for the defendant. As a result, the defendant's trial stakes are larger than the plaintiff's, so that he will invest more in effort and be more likely to win. More generally, the underdog has lower stakes at trial than the favorite, so that the favorite's effort incentives and, therefore, equilibrium winning probability, are higher than the underdog's.

With regards to the idea that the possibility of appeals increases the quality of legal decisions, it is important to note that the pro-favorite bias may be working in that 
direction or not (and in that sense be socially beneficial or harmful). As we will explain in detail in Section 4, it depends on the specific application whether the amplification of the initial advantage of the favorite regarding the probability of winning is socially desirable.

The concern that the possibility to appeal will contribute to an increase in the overall litigation costs is intuitive, since there may be two (instead of only one) legal contests. Our model can speak to this issue by comparing the total rent-seeking effort in a regime that permits appeals with the one in a single-stage regime. Whereas we find the named intuition confirmed in many scenarios, there are indeed cases in which the sum of expenditures is lower when appeals are possible. More specifically, the possibility of appeals increases litigation efforts if the effectiveness of legal arguments in the appeals court is high and the merits of the case are such that there is no clear favorite. However, the reverse will be true if legal arguments are not very effective in influencing the appeals court or there is a clear favorite. The latter result stems from the fact that the first contest is both less decisive on the award of damages and more asymmetric (due to the pro-favorite bias) than in a single-stage litigation contest. Both effects reduce rent-seeking incentives in the court of first instance.

Access to justice is another important matter on which the possibility of appeals may have a bearing. In this regard, we explore the plaintiff's incentives to bring a case. We find that the possibility of appeals makes a plaintiff less likely to bring suit if the appeals court's judgment depends sufficiently strongly on the litigants' effort choices. When, in contrast, the appeals court's decision is not at all responsive to legal arguments of the litigants, then allowing for appeals may in fact stimulate cases relative to the single-stage regime.

Our results concerning the relative overall litigation costs and the caseload are contingent on the effectiveness of the litigants' legal arguments regarding the appeals court's decision. In other words, the extent to which the parties feature an active role in appeals and thereby can have a bearing on the appeals court's decision is a policy variable that moderates the social benefit from the possibility of appeals. 
Related literature This paper is related to three strands of literature: contributions concerned with the appeals system, with litigation conceptualized as a contest, and with multi-stage contests.

First, we consider how the possibility of appeals influences litigants' choices in the trial stage. Most of the existing theoretical literature on appeals is concerned with their effect on judges' choices (e.g., Daughety and Reinganum (2000a), Iossa and Palumbo (2007), Levy (2005), Shavell (2006), Shavell (2007), Spitzer and Talley (2000)) or focuses on the losing litigant's incentives to file appeal (Shavell (1995), Shavell (2010)). The only exception that we are aware of is Wohlschlegel (2014), who analyzes the effect of the appeals system on pre-trial and post-trial settlement bargaining by asymmetrically informed litigants, taking litigation costs as given. By contrast, we endogenize litigation costs while assuming for simplicity that litigants are symmetrically informed and cannot settle out of court. Hence, both papers are complementary.

Most of the empirical literature on appeals such as Clermont and Eisenberg (2001) or Eisenberg and Heise $(2009,2015)$ is concerned with identifying and explaining systematic biases in the winning probabilities at appeals courts: Specifically, these papers find that the overwhelming majority of appeals judgments are affirmations and that plaintiffs are even less likely to achieve a reversal than defendants. The first of these findings supports our assumption that the trial judgment has a direct impact on winning probabilities in the appeals stage. Furthermore, our result that incentives for litigation effort at trial are higher for favorites than for underdogs implies that the favorite is more likely to win in both instances than the pure merits of the case would suggest. This increases the affirmation rate further beyond the direct effect that we assume, thus contributing to explaining the high affirmation rate theoretically $\left.\right|^{3}$

Second, we adopt the notion that litigation can be conceptualized as a (potentially biased) contest introduced by Katz (1988), and axiomatized and further analyzed by Hirshleifer and Osborne (2001). A biased contest success function has subsequently been

\footnotetext{
${ }^{3}$ The empirical finding regarding the high affirmation rate is also consistent with judges using the trial court as a signal in a Bayesian learning sense.
} 
used, always assuming that parties have full information about all relevant aspects when determining the level of effort, to analyze issues such as fee-shifting rules (e.g. Farmer and Pecorino (1999), Chen and Wang (2007) or Gürtler and Kräkel (2010)), delegation to lawyers and their compensation (Wärneryd (2000), Baik and Kim (2007a) or Baik and Kim (2007b)), the comparison between adversarial and inquisitorial rules (Parisi (2002)), the comparison between common and civil law in general (Luppi and Parisi (2012)) or legal presumptions (Bernardo, Talley, and Welch (2000)).

While all of these papers model litigation as a single-stage contest, the litigation process analyzed by Daughety and Reinganum (2000b), that starts only after settlement negotiations have failed, is made up of two stages and is, therefore, most closely related to our model: In their model of 'bifurcated' litigation, the question of fault is determined in the first stage, whereas the second stage is concerned with the level of damages to be awarded. As the second stage is only ever reached when the plaintiff has succeeded in the first stage, litigants will anticipate that the costs of the second stage only occur in that case, which makes winning in the first stage less (more) attractive for the plaintiff (defendant), thus giving rise to a 'pro-defendant bias'. We find the same effect in our model when parameters are such that the plaintiff would never appeal after losing at trial. However, we argue that, in the context of the appeals system, this bias is not tied to the role of the defendant but rather driven by the question of who will eventually file appeal. As the case in which one of the litigants would never file appeal can only occur if the other litigant is the favorite, this effect contributes to our pro-favorite bias. Furthermore, we show that the pro-favorite bias is not reliant upon an asymmetry in the incentives to file appeal as it exists even if both litigants are anticipated to appeal after losing at trial.

Last, our model is related to the literature on multi-stage contests with symmetric information. $]^{4}$ Klumpp and Polborn (2006) study the candidates' investment incentives in primary elections in the United States, which are organized as a sequence of regional elections. In their analysis, the sequentiality of elections introduces an asymmetry in

\footnotetext{
${ }^{4}$ For models with asymmetrically informed contestants see, e.g., Münster (2009), Powell (2007) or Slantchev (2010).
} 
stakes that causes, similar to the pro-favorite bias in our model, favorites in an asymmetric race to be more likely to win than if stages were played simultaneously. Our paper's contribution to this line of literature is to show that these effects carry over to the case with costly (and endogenous) entry to later stages of the contest, and to examine the impact of the sequentiality of the contest on aggregate rent-seeking incentives and how this impact depends on the parameters of the contest success function. Other papers in this line of literature analyze the impact of informative public signals on the contestants' relevant strength (Denter and Sisak (2015)) or endogenous timing choices when contestants decide on their efforts sequentially (e.g., Yildirim (2005)). While all these papers consider probabilistic contest success functions, there is also a related literature on multistage all-pay auctions (e.g. Konrad and Kovenock (2009)) in which the contestant with higher effort wins.

Plan of the paper The paper is organized in the following way: Section 2 presents the model assumptions. In Section 3, the equilibrium is determined for different parameter constellations. These results are used in Section 4 to discuss the impact of the appeals system on justice, equilibrium rent-seeking incentives, and access to justice. Section 5 summarizes and discusses possible extensions.

\section{The Model}

We analyze the choices of a plaintiff ('she') and a defendant ('he') regarding how much effort to expend in litigation that always comprises a trial stage and may include an appeals stage, along with the plaintiff's filing decision, the defendant's choice about whether or not to settle the case right away by paying full damages instead of going to court, and the losing litigant's decision of whether or not to file appeal. The litigation concerns the possible payment of a fixed amount from the defendant to the plaintiff. Both the trial court's and the appeals court's judgments will depend stochastically on the litigants' effort choices and the merits of the case. The merits of the case are unknown to courts but 
perfectly observable by both litigants. The appeals court's judgment will additionally depend directly on the trial court's judgment in a way explained below.

Before we describe our model in more detail, we briefly comment on two important modeling assumptions: We consider a setup in which settling the case is possible only by paying the full damages to the plaintiff and in which, by the time litigants' effort decisions are due, any informational asymmetries between them have been resolved. This latter assumption follows the existing literature on litigation contests and seems realistic as lawsuits unfold dynamically, so that the decision on the marginal unit of effort is made after a substantial amount of information has been revealed in court $5^{5}$ Ruling out settlement bargaining seems more restrictive, especially as we explicitly analyze the plaintiff's incentives to bring suit and the defendant's incentives to avoid going to court by paying the claim. This assumption allows us to assume symmetric information throughout the game and, therefore, is made for technical convenience as our main focus is on the litigants' effort decisions in either stage of jurisdiction. Note that the outcome of the litigation contest would be anticipated in pretrial settlement bargaining as in Chen and Wang (2007) in the same way as it is in our coarse all-or-nothing modeling of settlement. ${ }^{6}$

Timing The game consists of the following stages:

1. Filing suit: The plaintiff decides whether to file suit, and the defendant decides whether to defend himself.

2. Trial: Litigants invest effort in trial court, and the trial court's judgment is determined and announced.

3. Filing appeal: The litigant who lost in trial decides whether to file for appeal, and

\footnotetext{
${ }^{5}$ For instance, Chen and Wang (2007) consider a model of settlement bargaining with incomplete information with an ensuing litigation contest at trial. They argue that it is reasonable to assume that only the pretrial negotiation is governed by asymmetric information, whereas the private information is revealed after the trial has started but before effort decisions are made.

${ }^{6}$ The complementary paper Wohlschlegel (2014) considers how the possibility of appeals bears on settlement bargaining under asymmetric information for given litigation costs, and allows for asymmetric information to be only partially resolved at trial.
} 
the winning litigant decides whether to actually go to court if appeal has been filed.

4. Appeal: Litigants invest effort in appeals court, and the appeals judgment is determined and announced.

5. Payoffs are realized.

In Stage 1, we are considering the following sequence of steps: The plaintiff first decides whether to file suit. If she does not, the game ends with no damages being paid. If she does, the defendant chooses whether or not to defend himself. If he does not, the game ends, and he pays damages to the plaintiff. If he does, the plaintiff decides whether to indeed take the case to court or to withdraw. If she withdraws, the game ends with no damages being paid. If she takes the case to court, the game proceeds to Stage 2.7

In Stage 2, plaintiff and defendant simultaneously determine trial litigation efforts $p_{T}$ and $d_{T}$, respectively. Litigation effort is a one-dimensional index of inputs such as attorney hours, pages of documentation, etc. We abstract from any agency issues in the litigant-attorney relationship (see, e.g., Wärneryd (2000)). Stage 2 is concluded by the trial court's judgment according to a contest success function specified below.

In Stage 3, the sequence of Stage 1 is repeated where the party defeated in trial first decides whether to bring the appeal, the victorious litigant in trial chooses whether or not to defend in the appeals court, and the defeated party ultimately decides about actually filing the appeal.

In Stage 4, plaintiff and defendant simultaneously determine efforts in appeals court, $p_{A}$ and $d_{A}$, respectively. The appeals court's judgment results from a contest success function where both the merits of the case and the trial court's judgment interact with

\footnotetext{
${ }^{7}$ Using this microstructure for the filing Stages 1 and 3, we are taking account of the fact that there is little commitment power. For instance, a plaintiff might bring suit even if the lawsuit has negative expected value for her, hoping the defendant won't defend himself if his expected payoff from going to court is negative (which may be the case if court fees and equilibrium efforts are high). In our setup, such an action would not be credible, since the plaintiff can withdraw the action should the defendant decide to defend himself, which the defendant will anticipate and defend himself even if the lawsuit had negative expected value for him. A similar game structure is also used by Nalebuff (1987) in order to impose credibility of pretrial settlement offers.
} 
contest effort.

The Contest Success Function at the Trial and the Appeals Stage We extend prior analyses of litigation contests by the possibility of appeal. With regard to the trial court's judgment, we follow the previous literature and assume that the plaintiff's success probability is (see, e.g., Hirshleifer and Osborne (2001)).

$$
\pi_{T}\left(p_{T}, d_{T}, Y\right)=\frac{p_{T}^{\tau} Y}{p_{T}^{\tau} Y+d_{T}^{\tau}(1-Y)}
$$

where $Y \in(0,1)$ represents the merits of the plaintiff's case and the force exponent $\tau \in(0,1]$ weights the relative importance of effort and merit in determining the trial outcome and may thus be interpreted as the effectiveness of legal arguments in influencing the trial court's judgment (e.g., Farmer and Pecorino (1999)).

The parameter $Y$ is of key importance for our results. Katz (1988) explains that the merits of the plaintiff's case reflect the state of facts, the law, and the average judicial attitudes of the legal system as a whole. In Daughety and Reinganum (2000b), a very similar parameter moderates the likelihood with which the defendant is found liable for any given evidence (paralleling what a variation in $Y$ does for fixed levels of effort in our setup), and is interpreted as "the breadth of the court's interpretation of the applicable law, with a broader interpretation working against D" (i.e., the defendant). Bernardo, Talley, and Welch (2000) introduce a similar parameter that represents the role of a legal presumption, meant also as a shortcut for burdens of production/proof. Along these lines of interpreting legal presumptions as "a judicially applied prediction of factual or legal probability" (Garner (2011)), the level of $Y$ may be seen in the tort context, for instance, as the probability that an injurer has actually caused the accident (in a setup with uncertainty over causation) or as the probability that the injurer has failed to take due care under the negligence rule (in a setup with private information about care-taking).

In line with these interpretations, we will treat the level of $Y$ as a parameter that - for the law as it stands - classifies a case as having legal presumptions favoring the plaintiff (defendant) when $Y>(<) 1 / 2$. A greater distance $\left|Y-\frac{1}{2}\right|$ means stronger presumptions. 
More specifically, we define $Y$ as the probability that the plaintiff wins at trial if both litigants choose identical effort levels. In our conclusion, we briefly discuss endogenizing the level of $Y$, that is, its use as a policy variable.

Turning to the eventual judgment of the appeal's court, we assume that

$$
\pi_{A}\left(p_{A}, d_{A}, Z(\ell)\right)=\frac{p_{A}^{\alpha} Z(\ell)}{p_{A}^{\alpha} Z(\ell)+d_{A}^{\alpha}(1-Z(\ell))},
$$

where

$$
Z(\ell):=\lambda \ell+(1-\lambda) Y
$$

denotes the strength of the plaintiff's case in the appeals court. Thus, we follow the literature on single-stage litigation contests by assuming that bias moderates the importance of litigation effort and, for our second-stage litigation contest, assume that this bias is not only based on the true merits $Y$ of the case but also on the trial judgment $\ell$, where $\ell=1(\ell=0)$ applies when the plaintiff (defendant) prevailed in trial court.$^{8} \lambda \in(0,1)$ is the weight with which the trial judgment impacts on the plaintiff's strength of the appealed case $Z(\ell)$ and $\alpha \in(0,1]$ proxies the effectiveness of legal arguments in influencing the appeals court's judgment.

The assumption that the trial court's judgment has a direct impact on the success probabilities in the appeals stage reflects the fact that, in reality, appeals decisions are never made completely independent of earlier decisions $!^{9}$ The most obvious reason for this is that the purpose of appeals courts is to correct potential errors at the trial stage, and that the scope for this appellate error correction is limited by law in most jurisdictions. ${ }^{10}$ Furthermore, it appears likely that there will be a bias towards confirming the decision of the trial court due to, for example, respect for the other tribunal, an interest in establishing trust in verdicts, and an ingroup bias stemming from a shared identity with

\footnotetext{
${ }^{8}$ Note that this potential bias does not make the appeals system inherently inaccurate. We will show that, for symmetric contest efforts, the ex-ante probability that the plaintiff wins a case that is appealed (i.e., the probability before suit is even filed) is $Y$, as would be true in the single-stage benchmark.

${ }^{9}$ There is a wide consensus in the legal literature that 'appellate judges should and do lean toward affirmance as the usual course' (Clermont and Eisenberg (2002)).

${ }^{10}$ In the US, for instance, the Seventh Amendment of the Constitution confines error correction by appeals courts to questions of law rather than facts previously determined by a jury.
} 
the other legal decision-maker. Since the impact of the trial judgment varies across jurisdictions 11 we use $\lambda$ to measure the scope of appellate review. By allowing for different weights $\lambda$, we can therefore distinguish scenarios in which the appeals court is not very much constrained by the decision of and the facts established at the court of first instance (small levels of $\lambda$ ) from cases in which the trial court's judgment has a strong influence (high $\lambda$ ).

As another potential difference between success probabilities on trial and appeals court levels, our model allows for the possibility that the appeals court's judgment may be influenced by effort to a different extent by allowing for $\alpha \neq \tau$.

Payoffs The risk-neutral plaintiff and defendant litigate over the payment of damages normalized to 1 . We will obtain circumstances in which the defendant agrees to transfer damages without creating additional costs (specifically, when the plaintiff wants to file the case but the defendant would rather not defend in trial court). But, more generally, parties will incur costs in the legal battle. The trial (appeal) stage is associated with fixed court costs amounting to $c_{T}\left(c_{A}\right)$ for both litigants (i.e., we assume that the socalled American rule of cost allocation applies). Litigation effort creates linear costs in monetary terms precisely at the level of effort (i.e., we assume that the marginal effort cost is equal to one).

In summary, both litigants' payoffs are zero if the plaintiff does not file suit or withdraws the case, and the plaintiff's payoff is 1 and the defendant's is -1 if the plaintiff files suit but the defendant does not defend himself. If the case goes to trial, payoffs are

$$
\begin{aligned}
& W_{P}\left(p_{T}, d_{T}, Y\right)=V_{P}^{0}+\pi_{T}\left(p_{T}, d_{T}, Y\right)\left(V_{P}^{1}-V_{P}^{0}\right)-p_{T}-c_{T} \\
& W_{D}\left(d_{T}, p_{T}, Y\right)=V_{D}^{0}+\pi_{T}\left(p_{T}, d_{T}, Y\right)\left(V_{D}^{1}-V_{D}^{0}\right)-d_{T}-c_{T},
\end{aligned}
$$

where $V_{i}^{\ell}$ denotes litigant $i$ 's continuation payoff after the trial has ended with outcome $\ell$. In particular, $V_{P}^{\ell}=\ell=-V_{D}^{\ell}$ if appeal is not filed or withdrawn, $V_{P}^{\ell}=1-\ell=$

\footnotetext{
${ }^{11}$ Civil law countries often allow for some new fact finding even in the appeals court, and some appellate fact finding has recently been observed even in the United States (Bassett (2002)).
} 
$-V_{D}^{\ell}$ if appeal is filed but the victorious litigant in trial does not defend, and $V_{P}^{\ell}=$ $\pi_{A}\left(p_{A}^{\ell}, d_{A}^{\ell}, Z(\ell)\right)-p_{A}^{\ell}-c_{A}=: A_{P}^{\ell}$ and $V_{D}^{\ell}=-\pi_{A}\left(p_{A}^{\ell}, d_{A}^{\ell}, Z(\ell)\right)-d_{A}^{\ell}-c_{A}=: A_{D}^{\ell}$ if the case actually goes to the appeals court (where $p_{A}^{\ell}$ and $d_{A}^{\ell}$ indicate anticipated equilibrium effort at the appeals stage).

\section{Characterization of Equilibrium}

We proceed by backward induction and suppose that the plaintiff had filed suit in stage 1 , the trial court judgment was $\ell \in\{0,1\}$, and the litigant who had lost in trial court filed appeal.

Effort in Appeals Court The subgame at the appeals stage is identical to the litigation contest discussed in Hirshleifer and Osborne (2001), with $Z(\ell)$ representing the merits of the case, and damages at stake and the marginal cost of effort set equal to 1 . Parties seek to

$$
\begin{array}{cc}
\max _{p_{A}} & \pi_{A}\left(p_{A}, d_{A}, Z(\ell)\right)-p_{A} \\
\max _{d_{A}} & -\pi_{A}\left(p_{A}, d_{A}, Z(\ell)\right)-d_{A} .
\end{array}
$$

For such a litigation contest, it is a well-known result (as established in Hirshleifer and Osborne (2001), for example) that, given trial court judgment $\ell$, there exists a unique equilibrium in pure strategies for the effort choices in the appeals court given by

$$
p_{A}^{\ell}=d_{A}^{\ell}=\alpha Z(\ell)(1-Z(\ell))
$$

In equilibrium, the plaintiff wins with probability $\pi_{A}=Z(\ell)$, and payoffs of the appeals contest are

$$
\begin{aligned}
& A_{P}^{\ell}=Z(\ell)[1-\alpha(1-Z(\ell))]-c_{A} \\
& A_{D}^{\ell}=-1+(1-Z(\ell))[1-\alpha Z(\ell)]-c_{A} .
\end{aligned}
$$

which are the continuation payoffs after trial for cases that go to the appeals court, as defined in Section 2. Recalling that $Z(\ell)=\lambda \ell+(1-\lambda) Y$, it follows immediately that, in 
the special case where $\lambda=0$, the contest at the appeals stage is equivalent to the wellknown benchmark case of a single-stage contest. Furthermore, it is straightforward to show the intuitively plausible comparative-statics results that these continuation payoffs $A_{P}^{\ell}$ and $A_{D}^{\ell}$ are decreasing in the cost of an appeal $c_{A}$ and the force exponent $\alpha$ for both litigants, increasing (decreasing) in the merit of the plaintiff's case $Y$ for the plaintiff (defendant), and increasing (decreasing) in the impact $\lambda$ of the trial judgment for the litigant who has won (lost) in trial. Furthermore, $A_{P}^{\ell} \in\left[-c_{A}, 1-c_{A}\right]$ - where the lower (upper) bound is attained for $Z=0(Z=1)$ - and $A_{D}^{\ell} \in\left[-1-c_{A},-c_{A}\right]$ - where the lower (upper) bound is attained for $Z=1(Z=0)$. In the following analysis, we will sometimes refer to $A_{i}^{\ell}$ as $A_{i}^{\ell}(Y)$, thus emphasizing that these are functions of $Y$. An important property of these functions is that, for every $Y$ and $\ell, A_{P}^{\ell}(Y)=A_{D}^{1-\ell}(1-Y)+1$.

Another important feature of these continuation payoffs is how they depend on the outcome $\ell$ of the trial stage: When choosing effort levels at trial, litigants will anticipate the payoffs they can expect to get after winning and after losing at trial. In general, the difference in the payoffs after winning and the payoffs after losing a contest are referred to as the contest's stakes. In the case of the appeals stage, or the standard single-stage litigation contest analyzed in Hirshleifer and Osborne (2001), both litigants' stakes are the level of damages, as what the plaintiff gains when winning at court is equal to the defendant's loss. However, at the trial stage of our two-stage litigation contest, each litigant's stakes are the difference in the payoffs after winning and the payoffs after losing at trial. For instance, if litigants anticipate the case to go to the appeals court no matter which litigant wins at trial, the plaintiff's stakes at trial are $A_{P}^{1}-A_{P}^{0}$, and the defendant's are $A_{D}^{0}-A_{D}^{1}$. It will turn out that these stakes may be asymmetric, that is, there may be more at stake in trial court for one of the litigants than for the opposing side. The relative stakes, which we will denote by $S$ defined as the ratio of the defendant's over the plaintiff's stakes at trial, will play an important role in the equilibrium. The litigant for whom there is more at stake at trial will choose a higher trial effort level in equilibrium and, therefore, win with higher probability. 
Appeals Decision In this step, we analyze the decision by the litigant who lost in trial whether to file appeal, and the winning litigant's decision of whether to give in or to actually proceed to the appeals court, using backwards induction.

Suppose first that the defendant has won in trial $(\ell=0)$, the plaintiff has filed appeal, and the defendant has decided to defend himself. The plaintiff may either indeed take the case to the appeals court, which yields her $A_{P}^{0}$, or withdraw the appeal, which yields her zero. Hence, the plaintiff will take the case to the appeals court if and only if $A_{P}^{0} \geq 0$.

Consider now the defendant's decision of whether to defend himself after the plaintiff has filed appeal. Defending himself yields him $A_{D}^{0}$ if $A_{P}^{0} \geq 0$, and zero if $A_{P}^{0}<0$ (anticipating that the plaintiff would not really go to the appeals stage when $A_{P}^{0}<0$ ). Alternatively, he may just agree to pay damages to the plaintiff without taking the case to the appeals court, in which case the payoff is -1 . Hence, the defendant will not defend himself if and only if $A_{P}^{0} \geq 0$ and $A_{D}^{0}<-1$.

Last, consider the plaintiff's decision of whether to file appeal. Not filing appeal yields her zero payoff with certainty. If $A_{P}^{0} \geq 0$ and $A_{D}^{0}<-1$, she anticipates that the defendant will not defend himself, so that filing appeal yields her a payoff of 1, which she prefers to not filing appeal. If $A_{P}^{0} \geq 0$ and $A_{D}^{0} \geq-1$, the case will go to court if she files appeal and yield her $A_{P}^{0}$, which is positive by definition of this case, so that she strictly prefers filing appeal. If $A_{P}^{0}<0$ and the plaintiff files appeal, the defendant will defend himself, but the plaintiff will eventually withdraw the appeal. In this last case, the plaintiff is indifferent between filing and not filing appeal ${ }^{12}$ However, no matter how she decides, the outcome of this stage will be that the case does not go to the appeals court, and she does not receive any damages.

The analysis is similar for the case that the plaintiff has won in trial $(\ell=1)$. If $A_{D}^{1} \geq-1$, the defendant is always better off when filing appeal, no matter whether the plaintiff is anticipated to go to court or to give in. In the opposite case $A_{D}^{1}<-1$, the defendant is indifferent between filing and not filing appeal, since he anticipates to

\footnotetext{
${ }^{12}$ Recall that we disregard the pure filing costs for simplicity, and focus on the court fees for the actual court proceedings.
} 
withdraw the appeal eventually even if he files appeal, but he will pay damages without the case going to the appeals court.

The following proposition summarizes equilibrium play and payoffs in the subgame starting after a trial court judgment $\ell$, depending on the signs of the appeals payoffs $A_{i}^{\ell}$ defined in (10) and (11). It turns out that it may be optimal not to file appeal after losing at trial when the $\operatorname{costs} c_{A}$ of an appeal are too high. This affects the continuation value of a trial court outcome for each litigant, which we will denote $V_{i}^{\ell}$. Note that, if the case goes to the appeals court, $V_{i}^{\ell}=A_{i}^{\ell}$. However, if the case does not go to the appeals court, the continuation value $V_{i}^{\ell}$ is not equal to $A_{i}^{\ell}$ but rather $V_{P}^{0}=V_{D}^{0}=0$ if it is the plaintiff who lost at trial and does not appeal, or $V_{P}^{1}=-V_{D}^{1}=1$ if it is the defendant who lost at trial and does not appeal. As mentioned above, we denote the ratio of the defendant's to the plaintiff's stakes at trial, that is, the respective differences in continuation values as relative stakes $S$ defined by

$$
S:=\frac{V_{D}^{0}-V_{D}^{1}}{V_{P}^{1}-V_{P}^{0}}
$$

In order to prepare for the analysis of the litigants' effort decisions at trial that will follow further below, the following proposition also presents the continuation values and the stakes at trial for each of the discussed cases. The proof of this and subsequent propositions are relegated to the Appendix.

Proposition 1 (i) Both Litigants Appeal: If $0 \leq \min \left\{A_{P}^{0}, A_{D}^{1}+1\right\}$, then a trial court case will reach the appeals court independent of the trial court's judgment, and $V_{i}^{\ell}=A_{i}^{\ell}$. Trial court stakes are asymmetric when $Y \neq 1 / 2$ where

$$
S=\frac{1+\alpha(1-\lambda)(1-2 Y)}{1-\alpha(1-\lambda)(1-2 Y)}
$$

This scenario can only occur if $c_{A} \leq \frac{1-\lambda}{2}\left(1-\alpha \frac{1+\lambda}{2}\right)$, in which case there exists some $\hat{Y} \leq \frac{1}{2}$ such that this scenario occurs if and only if $\hat{Y} \leq Y \leq 1-\hat{Y}$.

(ii) Only Defendant Appeals: If $A_{P}^{0}<0 \leq \min \left\{A_{P}^{1}, A_{D}^{1}+1\right\}$, then a trial court case will reach the appeals court if and only if the plaintiff wins in trial. If the defendant 
wins in trial, the plaintiff will not file appeal. Furthermore, $V_{i}^{0}=0$ and $V_{i}^{1}=A_{i}^{1}$. Trial court stakes are asymmetric where

$$
S=\frac{[1-(1-\lambda)(1-Y)][1+\alpha(1-\lambda)(1-Y)]+c_{A}}{[1-(1-\lambda)(1-Y)][1-\alpha(1-\lambda)(1-Y)]-c_{A}}>1 .
$$

This case can arise only if $Y<\frac{1}{2}$.

(iii) Only Plaintiff Appeals: If $A_{D}^{1}+1<0 \leq \min \left\{A_{P}^{0}, A_{D}^{0}+1\right\}$, then a trial court case will reach the appeals court if and only if the defendant wins the trial. If the plaintiff wins the trial, the defendant will not file appeal. Furthermore, $V_{i}^{0}=A_{i}^{0}$ and $V_{P}^{1}=1=-V_{D}^{1}$. Trial court stakes are asymmetric where

$$
S=\frac{[1-(1-\lambda) Y][1-\alpha(1-\lambda) Y]-c_{A}}{[1-(1-\lambda) Y][1+\alpha(1-\lambda) Y]+c_{A}}<1 .
$$

This case can arise only if $Y>\frac{1}{2}$.

(iv) Trial Winner Does not Defend in Appeals Court: If $A_{P}^{1}<0 \leq A_{D}^{1}+1$ or $A_{D}^{0}+1<0 \leq A_{P}^{0}$, a trial court case will never reach the appeals court. If the first (second) condition holds, the plaintiff (defendant) who lost the trial does not file appeal and would not defend in appeals court even after winning the trial, in which case appeal is filed by the losing litigant. If the first (second) condition holds, then $V_{i}^{\ell}=0\left(V_{P}^{\ell}=1=-V_{D}^{\ell}\right)$. For both conditions, $V_{i}^{1}-V_{i}^{0}=0$. The first (second) condition can only be satisfied if $Y<\frac{1-2 \lambda}{2-2 \lambda}\left(Y \geq \frac{1}{2-2 \lambda}\right)$. Anticipating this outcome, such disputes do not even reach the trial stage.

(v) Neither Litigant Appeals: If $\max \left\{A_{P}^{0}, A_{D}^{1}+1\right\}<0$, appeal will not be filed, so that the trial court's judgment is upheld. Hence, $V_{i}^{0}=0$ and $V_{P}^{1}=1=-V_{D}^{1}$. The equilibrium is equivalent to that from single-stage litigation with force parameter $\tau$ and court fees $c_{T}$. This scenario can only occur if $c_{A}>\frac{1-\lambda}{2}\left(1-\alpha \frac{1+\lambda}{2}\right)$, in which case there exists some $\hat{Y} \leq \frac{1}{2}$ such that this scenario occurs if and only if $\hat{Y} \leq Y \leq 1-\hat{Y}$

Proposition 1 distinguishes five scenarios, four of which are represented graphically in Figure 1. The solid, increasing (dashed, decreasing) curve represents all pairs of $Y$ 
and $c_{A}$ such that the plaintiff's (the defendant's) net gain from the appeal after losing at trial, $A_{P}^{0}\left(A_{D}^{1}+1\right)$, is equal to zero. Recall first that $A_{P}^{\ell}$ is increasing and $A_{D}^{\ell}$ decreasing in $Y$, and both litigants' $A_{i}^{\ell}$ are decreasing in $c_{A}$. Furthermore, $A_{P}^{0}=-c_{A}$ for $Y=0$ and $A_{D}^{1}+1=-c_{A}$ for $Y=1$. Both curves intersect at $Y=1 / 2$ and $c_{A}=\frac{1-\lambda}{2}\left(1-\alpha \frac{1+\lambda}{2}\right)$.

Considering Figure 1, we note that the plaintiff prefers to file appeal after losing at trial for parameter combinations below the solid, increasing curve. The plaintiff files no appeal (is indifferent about whether to file appeal) for parameter combinations above (on) the solid, increasing curve. In other words, the plaintiff's payoff is continuous in $c_{A}$ and $Y$ at $A_{P}^{0}=0$. However, the defendant's payoff is discontinuous. Specifically, when the defendant won in trial court and parameters are such that the plaintiff prefers not to file appeal (i.e., combinations above the solid, increasing curve), the defendant's payoff is $V_{D}^{0}=0$, whereas it is $V_{D}^{0}=A_{D}^{0}<0$ when parameters are such that the plaintiff prefers to file appeal (i.e., combinations below the solid, increasing curve). In other words, the defendant's payoff is discontinuous at $A_{P}^{0}=0$. Intuitively, it is the plaintiff who decides whether the case goes to the appeals court after the plaintiff has lost at trial, so that her payoff after losing at trial is the maximum of the payoff with and without appeal. Similarly, the defendant's payoff is continuous and the plaintiff's payoff discontinuous at $A_{D}^{1}+1=0$ (i.e., combinations on the dashed, decreasing curve).

When Scenario (i) applies (i.e., when $c_{A}$ is sufficiently low and $Y$ takes intermediate values), a trial case will reach the appeals court independent of the trial court's judgment. This scenario is represented by the area below both curves in Figure 1. In contrast, the area above both curves in Figure 1, represents circumstances in which Scenario (v) arises, that is, when neither litigant wants to appeal the trial court's judgment. Low values of $Y$ (as represented by the area to the left of both curves in Figure 1) mean that the defendant is confident about his case. Losing at trial will put the plaintiff at an even greater disadvantage (as $Z(0)<Y$ ) and therefore discourage the plaintiff's filing of an appeal (Scenario (ii)). Low levels of $Y$ together with a low level of $\lambda$ and sufficiently high $c_{A}$ even allows for the case that the plaintiff would not defend her case in the appeals 


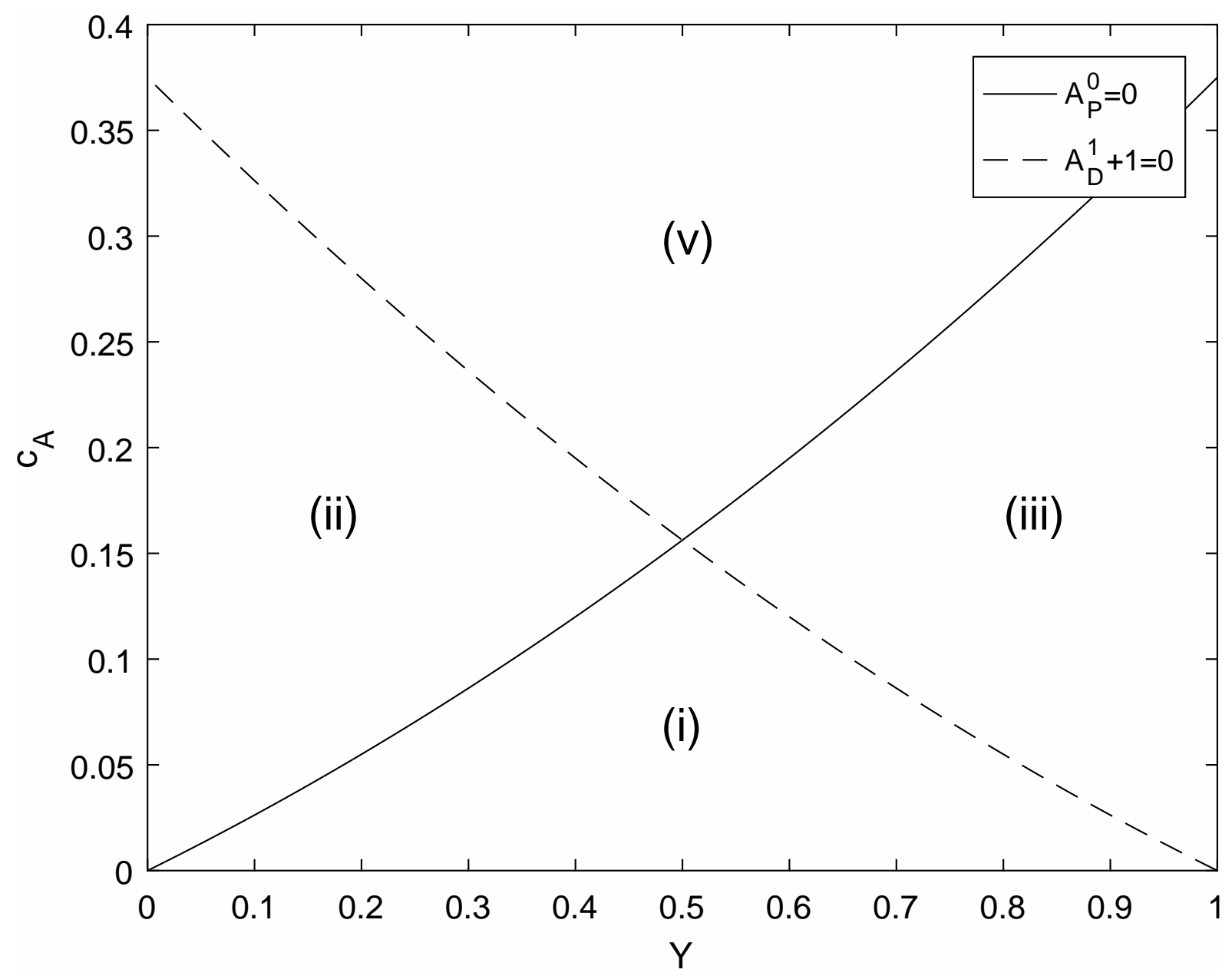

Figure 1: Scenarios of Proposition 1 (when $\lambda=1 / 2$ ). 
court after winning in trial court (Scenario (iv)).13 Anticipating that even a win in trial wouldn't yield the plaintiff any damages, there is no point in going to trial either, even if the trial court fees $c_{T}$ are negligible. In other terms, the possibility of a sufficiently costly appeal may deter some plaintiffs from filing cases with merit in the first place. We will provide a more detailed discussion of the incentives to file suit below (see Proposition 6 and the discussion thereof). A similar reasoning applies to the area to the right of both curves, where the defendant may not even defend a case in appeals court after winning in trial court when $\lambda<1 / 2$.

A common feature of Scenarios (i)-(iii), in which the case may reach the appeals stage, is that contest stakes at the trial stage are asymmetric (i.e., that $S \neq 1$ ) whenever $Y \neq \frac{1}{2}$ although litigants struggle over a damages payment of common value. Such an asymmetry of stakes is the driving force for the 'pro-defendant bias' in bifurcated trials identified by Daughety and Reinganum (2000b). In our model, a pro-defendant bias emerges when trial court stakes are higher for the defendant (i.e., when $S>1$ ). This is, indeed, the result in our Scenario (ii), which is analogous to the analysis in Daughety and Reinganum (2000b) in that the second stage will only be reached when the plaintiff won in the first stage.

However, our analysis shows that $S<1$ will occur in Scenario (iii) and, if $Y>\frac{1}{2}$, in Scenario (i). Recalling that Scenario (ii) (Scenario (iii)) can only occur if $Y<\frac{1}{2}(Y>$ $\frac{1}{2}$ ) this implies that, across Scenarios (i)-(iii), stakes are biased towards the defendant (plaintiff) if and only if $Y<\frac{1}{2}\left(Y>\frac{1}{2}\right)$. In other words, the pro-defendant bias in Daughety and Reinganum (2000b) stems from the fact that, in a bifurcated trial, the second stage is only reached after the plaintiff has won in trial, whereas in the context of appeals in which both litigants may choose to trigger the second stage after losing in trial, a pro-favorite bias results. We will elaborate on this issue in more detail in Section 4.

\footnotetext{
${ }^{13}$ For expositional clarity, we chose to base Figure 1 on $\lambda=\frac{1}{2}$, for which Scenario (iv) does not exist. For lower levels of $\lambda$, Scenario (iv) shows in the top left corner of the area to the left of both curves.
} 
Effort in Trial Court In Stage 2 of the game, litigants simultaneously decide how much effort to exert so as to increase their probabilities of winning in trial. The key difference of this stage in our game to the single-stage litigation contests analyzed in the prior literature lies in the stakes. Winning at trial does not necessarily settle the question of whether or not damages will be paid, but rather implies the continuation payoffs $V_{i}^{\ell}$ derived above. Parties seek to maximize (5) and (6) with respect to $p_{T}$ and $d_{T}$, respectively. The Nash-Cournot equilibrium for this contest is characterized in the following Proposition:

Proposition 2 There exists a unique equilibrium in pure strategies for the effort choices in the trial court given by

$$
p_{T}^{*}=\tau \pi_{T}^{*}\left(1-\pi_{T}^{*}\right)\left(V_{P}^{1}-V_{P}^{0}\right)=\frac{d_{T}^{*}}{S}
$$

and in which the plaintiff wins with probability

$$
\pi_{T}^{*}=\frac{Y}{Y+S^{\tau}(1-Y)}
$$

Expected equilibrium payoffs conditional on the case going to trial are

$$
\begin{aligned}
& \widehat{W}_{P}(Y)=V_{P}^{0}+\pi_{T}^{*}\left(1-\tau\left(1-\pi_{T}^{*}\right)\right)\left(V_{P}^{1}-V_{P}^{0}\right)-c_{T} \\
& \widehat{W}_{D}(Y)=V_{D}^{0}+\pi_{T}^{*}\left(1+\tau\left(1-\pi_{T}^{*}\right)\right)\left(V_{D}^{1}-V_{D}^{0}\right)-c_{T}
\end{aligned}
$$

where $\widehat{W}_{P}(Y)=\widehat{W}_{D}(1-Y)+1$, and $\widehat{W}_{P}(\cdot)$ is weakly increasing and $\widehat{W}_{D}(\cdot)$ weakly decreasing in $Y$.

Proposition 2 confirms the well-known result from single-stage litigation contests that a litigant $i$ 's equilibrium trial effort is equal to the force parameter $\tau$ times the equilibrium probabilities of winning and losing times litigant $i$ 's stake $V_{i}^{1}-V_{i}^{0}$. However, an important difference to single-stage contests is that the stakes and the equilibrium probabilities of winning are driven by the anticipated outcomes on the appeals stage: When $S \neq 1$, which we have shown to occur only if one of Scenarios (i)-(iii) applies, then the plaintiff's winning probability $\pi_{T}^{*}$ in the trial stage will be different from the merits of her case $Y$. In 
particular, $\pi_{T}^{*}>Y$ if and only if $S<1$ and, thus, if and only if $Y>1 / 2$. The divergence $\pi_{T}^{*}-Y$ is a measure of the pro-favorite bias that stems from the possibility of appeal.

Another characteristic that carries over from single-stage litigation contests is that equilibrium expected payoffs are monotonic in the merit of the plaintiff's case, $Y$. However, an important difference is that the anticipated appeals outcome depends on both litigants' appeals decisions as characterized in Proposition 1, so that the equilibrium expected payoffs will typically not be continuous at the boundaries of some scenarios of Proposition 1 (as discussed in the second paragraph after Proposition 1).

Decision of Filing Suit In the first step of the game, the plaintiff decides whether to file suit. If she does, the defendant may defend himself and, if so, the plaintiff has an opportunity to withdraw the case if she wishes so. Strategically, these decisions are similar to the appeals decision analyzed above in Step 3 of the game for the case in which the plaintiff has lost in trial: In both situations, the plaintiff won't receive anything unless she files suit (appeal), but will obtain damages with certainty if she files suit (appeal) and the defendant does not defend himself. Hence, depending on the equilibrium payoffs in the trial contest given by $(15)$ and $(16)$, the case will go to trial court if and only if $\widehat{W}_{P} \geq 0$ and $\widehat{W}_{D} \geq-1$, the plaintiff files suit without the defendant defending himself if $\widehat{W}_{P} \geq 0$ and $\widehat{W}_{D}<-1$, and the plaintiff won't file suit otherwise. The expected equilibrium payoffs are, therefore,

$$
\begin{aligned}
& W_{P}^{*}(Y)= \begin{cases}\min \left\{\widehat{W}_{P}(Y), 1\right\}, & \text { if } \widehat{W}_{P}(Y) \geq 0 \\
0, & \text { otherwise. }\end{cases} \\
& W_{D}^{*}(Y)= \begin{cases}\max \left\{\widehat{W}_{D}(Y),-1\right\}, & \text { if } \widehat{W}_{P}(Y) \geq 0 \\
0, & \text { otherwise }\end{cases}
\end{aligned}
$$

Recalling from Proposition 2 that both litigants' payoffs $\widehat{W}_{i}(Y)$ from going to trial are monotonic and symmetric, it follows that, if $c_{T}$ is small enough to make going to trial profitable for at least one litigant 14 there is a $\tilde{Y} \in(0,1)$ such that the case goes to trial if and only if $Y \in[\tilde{Y}, 1-\tilde{Y}]$. The case is not brought by the plaintiff if $Y<\tilde{Y}$

\footnotetext{
${ }^{14}$ Formally, this condition is $c_{T}<\frac{1}{2}\left(1-\frac{\alpha\left(1-\lambda^{2}\right)+\tau \lambda}{2}\right)-c_{A}$.
} 
and, if $Y>1-\widetilde{Y}$, the defendant pays damages in full to the plaintiff without going to court. Intuitively, as the plaintiff's (defendant's) equilibrium payoff from going to trial is increasing (decreasing) in $Y$, she (he) would not want to go to trial for very low (high) $Y$ and rather refrain from seeking damages (pay damages).

\section{Impact of the Possibility of Appeals}

In this section, we will examine how the possibility of appeals influences equilibrium outcomes and how both the size and sign of this impact depend on parameters that might be targeted by legal reform. To this end, we will compare certain features of our equilibrium with those of the equilibrium in the single-stage litigation (e.g., Hirshleifer and Osborne (2001)). In particular, we will discuss three issues that are most widely discussed in the literature on litigation contests, namely the relationship between the litigants' equilibrium winning probabilities and the merits of the plaintiff's case, the sum of equilibrium efforts, and access to justice for litigants with meritorious cases.

Case merits and equilibrium winning probabilities How trial outcomes relate to the underlying case facts is an important issue. When the merits of the plaintiff's case reflect the state of facts, the law, and the average judicial attitudes of the legal system as a whole (as argued by Katz (1988), for instance), then it may be socially undesirable when effort asymmetries induce a departure of the equilibrium winning probabilities from this benchmark. Accordingly, for instance, Hirshleifer and Osborne (2001) formulate the normative criterion of justice, stating on p. 186 that the "plaintiff's relative success should equal the defendant's degree of fault". However, whether this criterion is economically efficient - for instance, in providing incentives for a potential injurer to take care depends on the circumstances. An important distinction is whether threshold probability or proportional liability produces higher efficiency in the circumstances. For settings with uncertainty over causation, Shavell (1985) shows the superiority of proportional liability - that is, having damages equal to harm multiplied by the ex-post probability 
that the defendant has caused the accident - relative to threshold probability and all-ornothing rules. To be clear, our model does not allow for proportional liability, but from an ex-ante perspective of a defendant, proportional liability is equivalent to a scenario in which the plaintiff's equilibrium winning probability equals the ex-post probability that the defendant has caused the accident 15 If the merits of the case $Y$ in our model represent that ex-post probability, this reasoning implies that the plaintiff ought to win with probability $Y$ in equilibrium to ensure efficient primary incentives. In other words, the pro-favorite bias that results when appeals are possible is detrimental. In fact, when there is an amplification of the favorite's initial advantage, then a distortion with respect to the level of the activity is to be expected, for example (see Shavell (1985)).

There are also circumstances in which a threshold probability rule yields superior results. For example, in a unilateral-care model in which binary care is unobservable, Demougin and Fluet (2006) argue that incentives to take care are maximized by a rule where the defendant is held liable if it is more likely than not that actual care was below the standard (preponderance of evidence). In such circumstances with a threshold probability of $\frac{1}{2}$, when the merits of the plaintiff's case are such that it is more likely than not that the defendant failed to take due care (i.e., when $Y>\frac{1}{2}$ ), the plaintiff should win with certainty, implying that any uplifting of the equilibrium winning probability above the level of $Y$ is welcome from a social standpoint ${ }^{16}$

In the benchmark of a single-stage litigation contest, the plaintiff's success probability is exactly equal to $Y$, thereby performing ideally with regards to the justice criterion introduced by Hirshleifer and Osborne (2001). In our analysis including a trial court stage and possibly an appeals court stage, the equilibrium winning probability for the plaintiff at the appeals court is equal to $Z(\ell) \neq Y$. For the ex-ante probability of winning

\footnotetext{
${ }^{15}$ Note that we are disregarding the potential effects of the anticipated costs of a lawsuit on the incentives to take care in this informal discussion. Accounting for them properly requires a more formal analysis of the accident model which is beyond the scope of this paper.

${ }^{16}$ Farmer and Pecorino (2016) study an accident model in which injurer care is imperfectly observable, and plaintiff and defendant may settle in the shadow of a litigation system that induces a plaintiff's equilibrium probability of winning related to the merits of the plaintiff's case.
} 
the case overall, both the equilibrium probability of each possible trial court judgment and whether the first-instance court's judgment will be appealed must also be taken into account. These issues depend on the parameters as described in Proposition 1. If, for instance, the case will reach both courts with certainty (i.e., if Scenario (i) from Proposition 1 applies), the plaintiff's probability of being awarded damages is

$$
\pi^{*}=E \pi_{A}^{*}=E[Z(\ell)]=\pi_{T}^{*} Z(1)+\left(1-\pi_{T}^{*}\right) Z(0)=(1-\lambda) Y+\lambda \pi_{T}^{*}
$$

Clearly, the equilibrium winning probability $\pi^{*}$ will be equal to the merits of the case $Y$ only when the plaintiff's probability of winning in trial court $\pi_{T}^{*}$ is equal to the merits of the case. From Proposition 2, we know that $\pi_{T}^{*}>Y$ obtains when the plaintiff's stakes in the trial stage are larger than the defendant's (i.e, if and only if $S<1$ ), which results when the merits of the case imply that the plaintiff has a strong case (i.e., if and only if $Y>\frac{1}{2}$ ). In other words, the relatively greater stakes of the plaintiff in the trial stage when the plaintiff is the favorite incentivize relatively more plaintiff effort in the trial stage such that $\pi_{T}^{*}>Y$ obtains, which in turn implies $\pi^{*}>Y$. Since this argument applies to the defendant just as well, a pro-favorite bias results whenever the case reaches the appeals court with positive probability.

Proposition 3 Consider a case of strength $Y$ that has been brought in trial.

(a) If $0 \leq \max \left\{A_{P}^{0}, A_{D}^{1}+1\right\}$, in equilibrium, the plaintiff's ex-ante probability of being awarded damages is $\pi^{*}>(<) Y$ if and only if $Y>(<) 1 / 2$.

(b) If $\max \left\{A_{P}^{0}, A_{D}^{1}+1\right\}<0$, in equilibrium, a plaintiff's ex-ante probability of being awarded damages is $\pi^{*}=Y$.

Importantly, the pro-favorite bias is not a result of the assumed and realistic impact of the trial court's judgment on the appeals court's judgment (as manifested in equation (3)). In fact, it is entirely due to litigants' equilibrium choices: If litigants' efforts in each level of jurisdiction were symmetric, the plaintiff's expected probability of being awarded damages would be equal to $Y$ (as is true in single-stage litigation). However, 
with the possibility of appeals, the favorite has an incentive to make a larger effort in trial, because there is more at stake for her: Proposition 2 implies that the ratio of litigation efforts at the trial stage (i.e., $d_{T}^{*} / p_{T}^{*}$ ) is equal to the ratio of the differences in litigants' continuation values after winning and losing at trial (i.e., $S$ ), where the latter is different from 1 whenever $Y \neq 1 / 2$ and the case reaches the appeals court with positive probability.

Intuitively, if the case reaches the appeals court with certainty, litigants anticipate that equilibrium efforts in appeals court will be symmetric and the higher the closer $Z(\ell)$ is to $\frac{1}{2} \cdot{ }^{17}$ Hence, both litigants' equilibrium efforts in the appeals court tend to be low (high) when the favorite (underdog) won in trial. This effect increases (reduces) the favorite's (underdog's) effort incentives in the trial stage, thus making these incentives asymmetric. This effect is more pronounced in those scenarios in which the case only reaches the appeals court when the favorite lost in trial. In these instances, the favorite knows that she can decide the entire case by winning at trial, but also that a chance of reversal exists after losing in trial court. Since the chance of reversal requires the favorite's (underdog's) bearing the appeals court fees $c_{A}$, this further contributes to the asymmetry in trial effort incentives.

The following proposition analyzes the impact of the effectiveness of litigation effort at each level of jurisdiction on the size of the pro-favorite bias that may be proxied by $\left|\pi^{*}-Y\right|:$

Proposition 4 Suppose a case has been brought in trial and is anticipated to reach the appeals court with positive probability (Scenarios (i)-(iii)). The local comparative statics (i.e., that does not affect the appeals decision) of the absolute size of the pro-favorite bias $\left|\pi^{*}-Y\right|$ with respect to $\alpha$ and $\tau$ are strictly positive.

As the pro-favorite bias is driven by the favorite's (underdog's) benefit of lower equilibrium effort in the appeals court after winning (losing) at trial, an increase in $\alpha-$

\footnotetext{
${ }^{17}$ This is implied by (9) and in line with the well-known result that effort incentives are higher the more symmetric the contest is; see, for instance, Konrad (2009).
} 
implying that effort at the appeals stage is more productive - increases the size of this bias. Similarly, a higher effectiveness of trial effort amplifies the impact of the appeals stage on trial effort incentives and, thus, increases the pro-favorite bias. The effectiveness of the litigants' arguments with respect to the court decision at the trial and the appeal level is part of the design of the litigation system overall. As is clear from Proposition 4 , this influence allows to scale the pro-favorite bias up or down. The power of advocacy thereby addressed may attend to the influence of the lawyers' production and presentation of evidence, identification of suitable precedents or the interpretation of the law, for example.

In terms of legal design, the extent to which the appeals court relies on the trial court's judgment is also relevant to the size of the pro-favorite bias. In this regard, we find that an increase in the level of $\lambda$, that is, the influence of the trial court's judgment on the effective merits of the case in the appeals court, has an effect that is overall ambiguous. This general ambiguity results from two effects counteracting each other. Take Scenario (i) as an example. A higher level of $\lambda$ shifts importance away from the merits of the plaintiff's case $Y$ toward the equilibrium winning probability at the trial stage (as this channels the trial court decision's impact on the plaintiff's overall winning probability). This marginal influence is negative when $Y<1 / 2$. However, in this scenario, the increase in $\lambda$ also reduces the defendant's relative trial stakes, representing a marginal influence that is positive.

Litigation effort In litigation contests, the use of resources in litigation is an inefficient attempt at rent-seeking because the plaintiff's success probability without either litigant spending would be equal to the merits of the plaintiff's case. Accordingly, procedural changes that both lower total litigation effort and do not influence the justice attributes would be clearly efficiency enhancing.

In the single-stage benchmark, both litigants' equilibrium litigation efforts are symmetric and equal to the product of both litigants' success probabilities, the force parameter, and the contest stakes (which are set at 1 in our model). Hence, aggregate litigation 
effort in the single-stage benchmark litigation system is equal to

$$
\varepsilon_{B}=2 \tau Y(1-Y)
$$

In our analysis, we consider a sequence including the trial stage and possibly the appeals stage. At the trial stage, litigants compete for the head start granted by the victory at the court of first instance. Each litigant $i$ 's stakes in trial court are $V_{i}^{1}-V_{i}^{0}$. With Proposition 2, which shows that the aforementioned intuitive formula for equilibrium effort carries over to the trial court stage in our model, aggregate equilibrium efforts in trial are

$$
\varepsilon_{T}=\tau \pi_{T}^{*}\left(1-\pi_{T}^{*}\right)\left[\left(V_{P}^{1}-V_{P}^{0}\right)-\left(V_{D}^{1}-V_{D}^{0}\right)\right]
$$

Whereas the sum of the stakes in the single-stage benchmark is equal to 2 , the sum of the stakes represented in the square bracket in 21) is weakly smaller than 2 , as $V_{P}^{0} \geq-c_{A}$, $V_{P}^{1} \leq 1-c_{A}, V_{D}^{0} \geq-1-c_{A}$ and $V_{D}^{1} \leq-c_{A}$. Furthermore, the product of success probabilities at trial $\pi_{T}^{*}\left(1-\pi_{T}^{*}\right)$ is weakly smaller than $Y(1-Y)$. In summary, total trial court effort with the possibility of appeals is weakly smaller than the aggregate effort in the single-stage benchmark.

However, if the trial judgment is appealed, litigants will spend additional effort in the appeals stage. Hence, the more relevant comparison for policymakers is that between the sum of total efforts in both stages and the single-stage efforts. Note that, in the litigation game, the award of damages is just a transfer of wealth from the defendant to the plaintiff. Hence, the sum of both litigants' overall equilibrium payoffs $\widehat{W}_{P}(Y)+\widehat{W}_{D}(Y)$ must be equal to the negative of total costs, consisting of effort and court costs. With this insight, we can write aggregate total litigation effort as

$$
\begin{aligned}
& \varepsilon=-\left(\widehat{W}_{P}(Y)+\widehat{W}_{D}(Y)\right)-2 c_{T}-2 q_{A} c_{A} \\
& =\tau \pi_{T}^{*}\left(1-\pi_{T}^{*}\right)\left[\left(V_{P}^{1}-V_{P}^{0}\right)-\left(V_{D}^{1}-V_{D}^{0}\right)\right]-\pi_{T}^{*}\left(V_{P}^{1}+V_{D}^{1}\right)-\left(1-\pi_{T}^{*}\right)\left(V_{P}^{0}+V_{D}^{0}\right)-2 q_{A} c_{A},
\end{aligned}
$$

where $q_{A}$ denotes the ex-ante probability that a case reaches the appeals stage and is equal to one in Scenario (i) of Proposition 1, equal to $1-\pi_{T}^{*}$ in Scenario (ii), and equal 
to $\pi_{T}^{*}$ in Scenario (iii). The second line of $(22)$ has been obtained by using (15) and (16) to substitute for $\widehat{W}_{P}(Y)$ and $\widehat{W}_{D}(Y)$. Inspection of that second line reveals that the first summand is what has been identified in (21) to be aggregate effort at trial, so that the remainder, $-\pi_{T}^{*}\left(V_{P}^{1}+V_{D}^{1}\right)-\left(1-\pi_{T}^{*}\right)\left(V_{P}^{0}+V_{D}^{0}\right)-2 q_{A} c_{A}$ (which is readily verified to be non-negative), must be aggregate effort at the appeals stage.

The implications for overall litigation costs may be a concern when the desirability of the possibility to appeal is in question. When comparing $\varepsilon$ with the single-stage benchmark $\varepsilon_{B}$, it turns out that introducing the possibility of appeals may increase or reduce aggregate total litigation effort in equilibrium. Hence, it is important to know which parameters make the former or latter effect more likely.

Proposition 5 Suppose a case has been brought in trial and is anticipated to reach the appeals court with positive probability (Scenarios (i)-(iii)).

(a) Litigants' aggregate equilibrium effort level with the possibility of appeal, $\varepsilon$, is smaller than aggregate effort in the single-stage benchmark, $\varepsilon_{B}$, if (i) $\alpha$ is sufficiently small or (ii) $Y$ is sufficiently close to either 0 or 1 and $\tau>\lambda \alpha$.

If $Y$ is sufficiently close to $1 / 2$, in which case only Scenario (i) is relevant, then the difference between litigants' aggregate equilibrium effort level with the possibility of appeal and that in the single-stage benchmark, $\varepsilon-\varepsilon_{B}$, is

(b) positive for $\alpha \geq \tau$,

(c) strictly increasing in $\alpha$, and

(d) strictly increasing (decreasing) in $\lambda$ if $\alpha \lambda<(>) \frac{\tau}{2}$.

Both the effectiveness of legal arguments in appeals court $\alpha$ and the influence of the trial court's judgment on the effective merits of the case in the appeals court $\lambda$ have a direct influence on effort incentives at the appeals stage and an indirect effect on incentives at the trial stage (via the contest stakes in trial court). With $\alpha$ close to zero, the profavorite bias and the effort incentives at the appeals stage are negligible. This means that 
the possibility of appeal can influence trial stage incentives only via the stakes that are smaller than in the single-stage litigation benchmark, leading to lower efforts (Result (a) in Proposition 5). If effort at the appeals stage has a larger effect on the appeals court's judgment (i.e. larger $\alpha$ ), then effort incentives at the appeals stage increase - ceteris paribus - but at the same time the pro-favorite bias becomes more pronounced. As a result, equilibrium success probabilities at the trial stage move away from $1 / 2$, reducing aggregate equilibrium efforts at the trial stage. If $Y=1 / 2$, the latter effect vanishes, which yields Result (c) in Proposition 5. Result (b) shows that the positive effect of $\alpha$ on aggregate effort identified in Result (c) is sufficient to push the aggregate effort above the equilibrium level in the single-stage benchmark.

If the appeals court's judgment is to a greater extent influenced by the trial court's judgment (larger $\lambda$ ), the stakes in the trial stage increase (arguing for higher trial court efforts), but the contest at the trial stage becomes more asymmetric (arguing for lower trial court efforts). Part (d) of the Proposition shows that the former (latter) effect dominates if $\alpha$ and $\lambda$ are sufficiently small (large).

Access to Justice A concern that is repeatedly raised by the public is that high litigation costs may discourage legitimate cases from being brought, thereby restricting access to justice for some plaintiffs. Since litigation costs are partly endogenous in our model, it seems natural to discuss the impact of appeals on access to justice within our model. However, doing so requires a definition of which cases are legitimate and should be brought. For instance, Landeo and Nikitin (2018) analyze a model in which cases vary with regards to the level of damages that the court would award when ruling in the plaintiff's favor. They find that some cases will not proceed to court even though damages would be positive (but small), thereby establishing a lack of access to justice.

In our model, cases vary with regards to merit, making it is less straightforward to determine which cases should be brought from a society's point of view. As argued above, this will depend on the circumstances. For instance, one might follow the logic of preponderance of evidence and argue that a case is legitimate if and only if $Y>1 / 2$. 
Alternatively, one might acknowledge that all cases with $Y>0$ have some merit, so that the plaintiff should be awarded damages with probability $Y$. In both interpretations, whether a case is brought ought to be monotonic in the case's merits. This monotonicity property holds in our setup, as shown in Proposition 2. For low $Y$, the plaintiff will not file suit, for intermediate $Y$, the case will be tried, and for high levels of $Y$, the plaintiff will file suit and the defendant will compensate the plaintiff without defending himself.

In the following discussion, we analyze whether a plaintiff is more or less likely to bring a case in a regime in which appeals are possible as compared to a single-stage benchmark, and how this question depends on the model parameters. Basically, there are two reasons why a plaintiff may be more or less inclined to go to court in a system with appeals than in a single-level system: Changes in equilibrium outcomes such as equilibrium effort levels or equilibrium success probabilities, and changes in the overall court fees. This latter channel makes the comparison between both systems somewhat arbitrary, because it would be very sensitive to assumptions on these court fees under either system. In order to avoid this problem, we focus on the first channel by keeping the overall (expected) court fees constant (i.e., we compare access to justice in our model with that in a single-stage regime which charges the same fees $c$ as the expected court fees in our model).

In general, a case goes to court if it is to both litigants' benefit (relative to the alternatives available). In the appeals stage, the litigant who has won at trial is more likely to win than she would be in a single-stage system. Hence, her incentives to go to the appeals court are higher than her incentives to go to court in the single-stage system, whereas the losing litigant's incentives are lower. Hence, if the favorite wins, the underdog is even less inclined to go to court, so that the case is less likely to reach the appeals court than a case would be to reach court in a single-stage system with the same court fees $c=c_{A}$. However, if a litigant's trial case had strong merit but was still lost at trial, he may be induced to appeal cases that wouldn't have gone to court in a single-stage system. As explained in Proposition 1, even extreme cases in which the case is not filed because even the winning litigant would not defend the case in appeal are 
possible (Scenario (iv)).

When contemplating whether to bring suit in the trial stage, the plaintiff anticipates these post-trial-court-judgment contingencies. In Scenario (i), where all cases ultimately end up in appeals court, shifting court fees from the trial to the appeals stage and vice versa while keeping total expected court fees constant does not have any effect on the decision to file the case. However, this is not true if only one of the litigants will challenge a loss at trial, because in this case the underdog will see the savings in court fees as a benefit of losing at trial and thus reduce equilibrium effort. If the plaintiff is the underdog, this will increase her incentives to bring suit in the first place.

The following proposition shows that a litigation system with the possibility of appeal may increase or decrease the probability that a case will be filed relative to a single-stage benchmark system, and how this depends on the model parameters. Recall from the end of Section 3 that, if there is some $Y$ at all such that a case would ever go to trial, there is a threshold level $\widetilde{Y}$ such that the plaintiff files suit if and only if $Y \geq \tilde{Y}$, and the defendant defends himself if and only if suit has been filed and $Y \leq 1-\tilde{Y}$. Hence, the analysis of the plaintiff's decision to bring suit can be confined to the case where $Y<1 / 2$ (i.e., the case in which the plaintiff is the underdog). Proposition 6 performs this analysis and points out that the same results carry over to the defendant's decision to defend himself if $Y>1 / 2$.

Proposition 6 Compare the set of $Y$ for which a case reaches trial court in a litigation system with the possibility of appeal to that set that emerges in a single-stage litigation system with identical expected court fees. The former set

(a) is a subset of the latter if $\alpha \geq \tau$,

(b) strictly contains the latter if $\alpha=0$ and $0 \leq \min \left\{A_{P}^{0}, A_{D}^{1}+1\right\}$ (i.e., in Scenario (i) of Proposition 1), and

(c) is diminishing in $\alpha$. 
Part (c) of Proposition 6 shows that, if the possibility of appeals has any effect, then a higher impact $\alpha$ of litigation efforts on the appeals judgment will make the case less likely to even be brought in trial. Intuitively, a higher level of $\alpha$ increases equilibrium efforts in the appeals stage. This reduces both litigants' continuation values (independent of who wins at trial) and increases the pro-favorite bias, implying a lower payoff from a lawsuit for the plaintiff if she is the underdog, which is the relevant case for the analysis of the plaintiff's incentives to bring suit (as argued above).

By contrast, when $\alpha$ is close to zero and the case reaches the appeals court with certainty (Scenario (i) of Proposition 1), then filing incentives are higher in a litigation system with the possibility of appeals because the appeals stage makes the overall result less dependent on litigation efforts. However, Part (a) shows that the negative effect of $\alpha$ on the incentives to bring the case to trial dominates if the impact of litigation effort on the appeals court's judgment is at least as large as that on the trial court's judgment $(\alpha \geq \tau)$.

\section{Conclusion}

Many legal systems allow parties dissatisfied with a first-instance authority's judgment to appeal their case to a higher decision-making authority, whereas some forms of alternative dispute resolution explicitly exclude this right. We have analyzed the impact of the possibility to appeal a first-instance authority's judgment on the equilibrium of a litigation contest. Anticipating the possibility of appeal induces the litigant with the stronger case to invest relatively more litigation effort into the trial case, thereby improving her overall success probability beyond the level that would be commensurate with the strength of her case in a single-stage litigation system. We thus conclude that the appeals system introduces a pro-favorite bias in judicial decision-making. We have argued that it will depend on the specific application whether such a bias is socially beneficial or harmful.

Furthermore, we have discussed the impact of appeals on rent-seeking incentives and the incentives to go to court: If the effectiveness of legal arguments in influencing the 
appeals court's decision is not higher than the one in the trial court and the merits of the plaintiff's and the defendant's cases are similar (i.e., there is no clear favorite), then the possibility of appeals unambiguously increases incentives for litigation effort and makes the filing of the case less likely compared to a single-stage system. However, if the effectiveness of legal arguments in the appeals court's decision is very low, both of these results are reversed. Interestingly, aggregate litigation effort may be lower with the possibility of appeal than in a single-stage system when the case's merits are sufficiently unbalanced (i.e., when there is a clear favorite).

With regards to recommendations for legal reform, our paper identifies a number of potential advantages of the possibility of appeal: First, making the favorite more likely to win may be socially beneficial whenever a preponderance-of-evidence rule is called for, which is the case, for instance, if injurers' care levels cannot be perfectly reconstructed in court. Second, while rent-seeking incentives tend to increase when the effectiveness of legal arguments is comparable in both courts and there is no clear favorite, introducing an appeals stage reduces litigation effort in very clear cases and makes these cases less likely to be tried. Third, we have described the implications from the possibility to appeal for different merits of the plaintiff's case when viewed for fixed legal presumptions. However, in a more general setup, the decision of whether or not to allow litigants to appeal may have repercussions on optimal legal presumptions.

Despite the immense practical importance of appeals systems, the literature is relatively scant. The present paper makes an attempt to shed some light on the mechanisms at play by referring to the litigation contest setup. However, it needs to be stressed that, while standard in the literature on litigation effort, the Tullock (1980) contest model is an extremely stylized representation of how courts decide. However, the model has proven quite rich in the existing literature on litigation contests and has yielded many plausible insights. Our objective was to present important mechanisms in a transparent way. To achieve this objective, we have abstracted from practically relevant issues such as potentially asymmetric information and the role of lawyers. These and other issues are left for future research. 


\section{Appendix}

\section{A Proof of Proposition 1}

The discussion leading to Proposition 1 implied that the continuation values for each litigant and each possible trial court judgment are:

$$
\begin{aligned}
& V_{P}^{0}= \begin{cases}\max \left\{A_{P}^{0}, 0\right\}, & \text { if } A_{D}^{0} \geq-1 ; \\
1, & \text { if } A_{D}^{0}<-1 \text { and } A_{P}^{0} \geq 0 ; \\
0, & \text { otherwise. }\end{cases} \\
& V_{D}^{0}= \begin{cases}\max \left\{A_{D}^{0},-1\right\}, & \text { if } A_{P}^{0} \geq 0 ; \\
0, & \text { otherwise. }\end{cases} \\
& V_{P}^{1}= \begin{cases}\max \left\{A_{P}^{1}, 0\right\}, & \text { if } A_{D}^{1} \geq-1 ; \\
1, & \text { otherwise. }\end{cases} \\
& V_{D}^{1}= \begin{cases}\max \left\{A_{D}^{1},-1\right\}, & \text { if } A_{P}^{1} \geq 0 ; \\
0, & \text { if } A_{P}^{1}<0 \text { and } A_{D}^{1} \geq-1 ; \\
-1, & \text { otherwise. }\end{cases}
\end{aligned}
$$

The continuation values build on the expected payoffs from the appeals stage (10) and (11), which may be stated in terms of the basic model parameters as follows:

$$
\begin{aligned}
A_{P}^{0} & =(1-\lambda) Y[1-\alpha(1-(1-\lambda) Y)]-c_{A} \\
A_{D}^{0}+1 & =[1-(1-\lambda) Y][1-\alpha(1-\lambda) Y]-c_{A} \\
A_{P}^{1} & =[1-(1-\lambda)(1-Y)][1-\alpha(1-\lambda)(1-Y)]-c_{A} \\
A_{D}^{1}+1 & =(1-\lambda)(1-Y)[1-\alpha(1-(1-\lambda)(1-Y))]-c_{A}
\end{aligned}
$$

As for this, note that

$$
A_{D}^{\ell}+1=1-2 Z(\ell)+A_{P}^{\ell}
$$

Using the definition of $Z(\ell)$, the following rankings of the $A_{i}^{\ell}, i=P, D$ can be established:

Lemma 1 (a) If $0 \leq Y<\frac{1-2 \lambda}{2-2 \lambda}$, then $A_{P}^{0}<A_{P}^{1}<A_{D}^{1}+1<A_{D}^{0}+1$.

(b) If $\frac{1-2 \lambda}{2-2 \lambda} \leq Y<\frac{1}{2}$, then $A_{P}^{0}<A_{D}^{1}+1 \leq A_{P}^{1}<A_{D}^{0}+1$.

(c) If $\frac{1}{2} \leq Y<\frac{1}{2-2 \lambda}$, then $A_{D}^{1}+1 \leq A_{P}^{0}<A_{D}^{0}+1 \leq A_{P}^{1}$. 
(d) If $\frac{1}{2-2 \lambda} \leq Y<1$, then $A_{D}^{1}+1<A_{D}^{0}+1 \leq A_{P}^{0}<A_{P}^{1}$.

Proof. Note first that $A_{P}^{0}<A_{P}^{1}$ and $A_{D}^{1}<A_{D}^{0}$. Using (31), $A_{D}^{1}+1-A_{P}^{1}=1-2 Z(1)=$ $1-2 \lambda-(2-2 \lambda) Y \leq 0$ if and only if $Y \geq \frac{1-2 \lambda}{2-2 \lambda}$. Furthermore, $A_{D}^{0}+1-A_{P}^{0}=1-2 Z(0)=$ $1-(2-2 \lambda) Y \leq 0$ if and only if $Y \geq \frac{1}{2-2 \lambda} \cdot A_{D}^{1}+1-A_{P}^{0}=(1-\lambda)(1-2 Y)(1-\lambda \alpha) \leq 0$ if and only if $Y \geq \frac{1}{2}$. Last, $A_{D}^{0}+1-A_{P}^{1}=(1-\lambda)(1-2 Y)(1+\lambda \alpha) \leq 0$ if and only if $Y \geq \frac{1}{2}$

Using Lemma 1, it is straightforward to establish the case distinctions made in Proposition 1 with respect to $Y$. The critical level for $c_{A}$ used in Scenarios (i) and (v) follows from evaluating either $A_{P}^{0}$ or $A_{D}^{1}+1$ at $Y=1 / 2$ since $\min \left\{A_{P}^{0}, A_{D}^{1}+1\right\}=A_{P}^{0}$ when $Y<1 / 2$ and $\min \left\{A_{P}^{0}, A_{D}^{1}+1\right\}=A_{D}^{1}+1$ when $Y \geq 1 / 2$, and observing that $A_{P}^{0}\left(A_{D}^{1}+1\right)$ is increasing (decreasing) in $Y$. The level of $\hat{Y}$ is then implied by the restriction $\min \left\{A_{P}^{0}, A_{D}^{1}+1\right\} \geq 0$ in Scenario (i) and $\max \left\{A_{P}^{0}, A_{D}^{1}+1\right\}<0$ in Scenario (v) and thus a function of $c_{A}$.

\section{B Proof of Proposition 2}

Proposition 2 makes claims about equilibrium choices and payoffs, the symmetry of equilibrium payoffs, and how they depend on $Y$. In the following, we will prove these claims one by one:

Part 1: Equilibrium Choices and Payoffs. Recall that, given that the case goes to trial court, plaintiff and defendant seek to

$$
\begin{aligned}
& \max _{p_{T}} V_{P}=V_{P}^{0}+\pi_{T}\left(V_{P}^{1}-V_{P}^{0}\right)-p_{T} \\
& \max _{d_{T}} V_{D}=V_{D}^{0}+\pi_{T}\left(V_{D}^{1}-V_{D}^{0}\right)-d_{T} .
\end{aligned}
$$

The first-order conditions are

$$
\begin{aligned}
& \left(V_{P}^{1}-V_{P}^{0}\right) \frac{\tau Y(1-Y) p_{T}^{\tau-1} d_{T}^{\tau}}{\left[p_{T}^{\tau} Y+d_{T}^{\tau}(1-Y)\right]^{2}}=1 \\
& \left(V_{D}^{0}-V_{D}^{1}\right) \frac{\tau Y(1-Y) p_{T}^{\tau} d_{T}^{\tau-1}}{\left[p_{T}^{\tau} Y+d_{T}^{\tau}(1-Y)\right]^{2}}=1
\end{aligned}
$$


Solving this system of equation yields the equilibrium efforts

$$
p_{T}^{*}=\tau Y(1-Y) \frac{\left(V_{P}^{1}-V_{P}^{0}\right) S^{\tau}}{\left[Y+(1-Y) S^{\tau}\right]^{2}}=\frac{d_{T}^{*}}{S},
$$

substituting for the equilibrium efforts in the CSF yields (14) which can be used to simplify equilibrium efforts to (13). Last, using (13) to substitute for equilibrium efforts in the payoff functions yields 15 and 16 .

Part 2: Symmetry. In this part we will prove that, for any $Y, \widehat{W}_{P}(Y)=\widehat{W}_{D}(1-Y)+1$. For this, note first that, for every $Y$ and $\ell, A_{P}^{\ell}(Y)=A_{D}^{1-\ell}(1-Y)+1$ follows from (27)(30). Hence, a case with merit $Y$ is in Scenario (i) (Scenario (v)) of Proposition 1 if and only if an otherwise identical case with merit $1-Y$ is also in that scenario. Furthermore, a case with merit $Y$ is in Scenario (ii) (Scenario (iii)) of Proposition 1 if and only if an otherwise identical case with merit $1-Y$ is in Scenario (iii) (Scenario (ii)). Last, a case with merit $Y$ is in the first case of Scenario (iv) of Proposition 1 if and only if an otherwise identical case with merit $1-Y$ is in the second case of Scenario (iv) and vice versa. As a consequence, it is easy to use Proposition 1 to check that this relationship extends to payoffs in cases that do not go to the appeals court, so that, for every $Y$ and $\ell, V_{P}^{\ell}(Y)=V_{D}^{1-\ell}(1-Y)+1$.

Next, representing the equilibrium probability that the plaintiff prevails as a function of $Y, \pi_{T}^{*}(Y)$, we will prove that $\pi_{T}^{*}(1-Y)=1-\pi_{T}^{*}(Y)$ :

$$
\begin{aligned}
\pi_{T}^{*}(1-Y) & =\frac{1-Y}{1-Y+\left(\frac{V_{D}^{0}(1-Y)-V_{D}^{1}(1-Y)}{V_{P}^{1}(1-Y)-V_{P}^{0}(1-Y)}\right)^{\tau} Y} \\
& =\frac{1-Y}{1-Y+\left(\frac{V_{D}^{0}(Y)-V_{D}^{1}(Y)}{V_{P}^{1}(Y)-V_{P}^{0}(Y)}\right)^{-\tau} Y} \\
& =\frac{\left(\frac{V_{D}^{0}(Y)-V_{D}^{1}(Y)}{V_{P}^{1}(Y)-V_{P}^{0}(Y)}\right)^{\tau}(1-Y)}{\left(\frac{V_{D}^{0}(Y)-V_{D}^{1}(Y)}{V_{P}^{1}(Y)-V_{P}^{0}(Y)}\right)^{\tau}(1-Y)+Y} \\
& =1-\frac{Y}{Y+\left(\frac{V_{D}^{0}(Y)-V_{D}^{1}(Y)}{V_{P}^{1}(Y)-V_{P}^{0}(Y)}\right)^{\tau}(1-Y)} \\
& =1-\pi_{T}^{*}(Y),
\end{aligned}
$$

where the second equality uses the relationship $V_{P}^{\ell}(Y)=V_{D}^{1-\ell}(1-Y)+1$ established 
above. Hence, for every $Y$,

$$
\begin{aligned}
\widehat{W}_{D}(1-Y)= & V_{D}^{0}(1-Y)+\pi_{T}^{*}(1-Y)\left(V_{D}^{1}(1-Y)-V_{D}^{0}(1-Y)\right) \\
& +\tau \pi_{T}^{*}(1-Y)\left(1-\pi_{T}^{*}(1-Y)\right)\left(V_{D}^{1}(1-Y)-V_{D}^{0}(1-Y)\right)-c_{T} \\
= & V_{P}^{1}(Y)-1+\left(1-\pi_{T}^{*}(Y)\right)\left(V_{P}^{0}(Y)-V_{P}^{1}(Y)\right) \\
& +\tau\left(1-\pi_{T}^{*}(Y)\right) \pi_{T}^{*}(Y)\left(V_{P}^{0}(Y)-V_{P}^{1}(Y)\right)-c_{T} \\
= & V_{P}^{0}(Y)-1+\pi_{T}^{*}(Y)\left(1-\tau\left(1-\pi_{T}^{*}(Y)\right)\right)\left(V_{P}^{1}(Y)-V_{P}^{0}(Y)\right)-c_{T} \\
= & \widehat{W}_{P}(Y)-1 .
\end{aligned}
$$

Part 3: Monotonicity. Let us start with taking the derivatives of the continuation payoffs from the appeals stage:

$$
\begin{aligned}
& \frac{\partial A_{P}^{0}}{\partial Y}=(1-\lambda)[1-\alpha(1-2(1-\lambda) Y)]>0 \\
& \frac{\partial A_{D}^{0}}{\partial Y}=-(1-\lambda)[1+\alpha(1-2(1-\lambda) Y)]<0 \\
& \frac{\partial A_{P}^{1}}{\partial Y}=(1-\lambda)[1+\alpha(1-2(1-\lambda)(1-Y))]>0 \\
& \frac{\partial A_{D}^{1}}{\partial Y}=-(1-\lambda)[1-\alpha(1-2(1-\lambda)(1-Y))]<0 .
\end{aligned}
$$

Note that $\frac{\partial A_{P}^{1}}{\partial Y}-\frac{\partial A_{P}^{0}}{\partial Y}=\frac{\partial A_{D}^{1}}{\partial Y}-\frac{\partial A_{D}^{0}}{\partial Y}=2 \alpha \lambda(1-\lambda)$.

Due to the symmetry shown in the second part of this Proof, it is sufficient to show monotonicity of one litigant's payoff, say, the plaintiff's. The derivative of the plaintiff's payoff in trial with respect to $Y$ is

$$
\widehat{W}_{P}^{\prime}(Y)=\left(1-\pi_{T}^{*}\left(1-\tau\left(1-\pi_{T}^{*}\right)\right)\right) \frac{\partial V_{P}^{0}}{\partial Y}+\pi_{T}^{*}\left(1-\tau\left(1-\pi_{T}^{*}\right)\right) \frac{\partial V_{P}^{1}}{\partial Y}+\left(1-\tau\left(1-2 \pi^{*}\right)\right)\left(V_{P}^{1}-V_{P}^{0}\right) \pi_{T}^{* \prime}
$$

where

$$
\pi_{T}^{* \prime}=\frac{S^{\tau-1}\left(S-Y(1-Y) \tau S^{\prime}\right)}{\left(Y+S^{\tau}(1-Y)\right)^{2}}
$$

is the first derivative of the plaintiff's equilibrium winning probability in trial with respect to $Y$. The derivatives $\frac{\partial V_{P}^{0}}{\partial Y}, \frac{\partial V_{P}^{1}}{\partial Y}$ and $S^{\prime}$ depend on the scenario of Proposition 1 1 . Within each of these scenarios, $\widehat{W}_{P}(Y)$ is weakly increasing in $Y$ : 
In Scenario (i), $\frac{\partial V_{P}^{0}}{\partial Y}=\frac{\partial A_{P}^{0}}{\partial Y}>0, \frac{\partial V_{P}^{1}}{\partial Y}=\frac{\partial A_{P}^{1}}{\partial Y}>0$ and

$$
S^{\prime}=\frac{\left(\frac{\partial A_{D}^{0}}{\partial Y}-\frac{\partial A_{D}^{1}}{\partial Y}\right)\left(A_{P}^{1}-A_{P}^{0}\right)-\left(\frac{\partial A_{P}^{1}}{\partial Y}-\frac{\partial A_{P}^{0}}{\partial Y}\right)\left(A_{D}^{0}-A_{D}^{1}\right)}{\left(A_{P}^{1}-A_{P}^{0}\right)^{2}}=-\frac{2 \alpha \lambda(1-\lambda)(1+S)}{A_{P}^{1}-A_{P}^{0}}<0 .
$$

In Scenario (ii), $\frac{\partial V_{P}^{0}}{\partial Y}=0, \frac{\partial V_{P}^{1}}{\partial Y}=\frac{\partial A_{P}^{1}}{\partial Y}>0$ and

$$
S^{\prime}=\frac{-\frac{\partial A_{D}^{1}}{\partial Y} A_{P}^{1}+\frac{\partial A_{P}^{1}}{\partial Y} A_{D}^{1}}{\left(A_{P}^{1}\right)^{2}}=-\frac{2(1-\lambda)\left[\alpha(1-(1-\lambda)(1-Y))^{2}+c_{A}\right]}{\left(A_{P}^{1}\right)^{2}}<0 .
$$

In Scenario (iii), $\frac{\partial V_{P}^{0}}{\partial Y}=\frac{\partial A_{P}^{0}}{\partial Y}>0, \frac{\partial V_{P}^{1}}{\partial Y}=0$ and

$$
S^{\prime}=\frac{\frac{\partial A_{D}^{0}}{\partial Y}\left(1-A_{P}^{0}\right)+\frac{\partial A_{P}^{0}}{\partial Y}\left(A_{D}^{0}+1\right)}{\left(1-A_{P}^{0}\right)^{2}}=-\frac{2(1-\lambda)\left[\alpha(1-(1-\lambda) Y)^{2}+c_{A}\right]}{\left(1-A_{P}^{0}\right)^{2}}<0 .
$$

In Scenario (iv), $\widehat{W}_{P}(Y)$ is not well defined. In Scenario (v), $\frac{\partial V_{P}^{0}}{\partial Y}=\frac{\partial V_{P}^{1}}{\partial Y}=S^{\prime}=0$. Summing up, this proves that, within each scenario, $\widehat{W}_{P}^{\prime}(Y) \geq 0$.

It remains to prove that monotonicity also holds at the boundaries between the Scenarios of Proposition 1. The following boundaries are potentially relevant for increasing $Y$ :

- Moving from Scenario (ii) to (i) and from Scenario (v) to (iii) by increasing $Y$ at $A_{P}^{0}=0: V_{P}^{0}$ and $V_{P}^{1}$ are continuous, and $V_{D}^{0}-V_{D}^{1}$ jumps downward from $0-A_{D}^{1}$ to $A_{D}^{0}-A_{D}^{1}$. Hence, $S$ jumps downward and, therefore, $\pi_{T}^{*}$ jumps upward. Overall, $\widehat{W}_{P}(Y)$ increases.

- Moving from Scenario (i) to (iii) and from Scenario (ii) to (v) by increasing $Y$ at $A_{D}^{1}=-1: V_{D}^{0}-V_{D}^{1}$ and $V_{P}^{0}$ are continuous, and $V_{P}^{1}$ jumps upward from $A_{P}^{1}$ to 1. Hence, $S$ jumps downward and, therefore, $\pi_{T}^{*}$ jumps upward. Over all, $\widehat{W}_{P}(Y)$ increases.

\section{Proof of Proposition 3}

Part (a) deals with the parameter range that supports Scenarios (i) - (iv) of Proposition 1. In the text leading to the proposition, the claim for Scenario (i) was supported by reference to (19). In Scenario (ii), we have that $\pi^{*}=\pi_{T}^{*} Z(1)<Y$ due to $S>1>\lambda$ in 
this scenario. In Scenario (iii), we have $\pi^{*}=\pi_{T}^{*}+\left(1-\pi_{T}^{*}\right) Z(0)>\pi_{T}^{*}>Y$ due to $S<1$. In Scenario (iv), the case does not even go to trial, so that this scenario is irrelevant for the proposition.

Part (b) deals with Scenario (v), in which the case does not go to the appeals court. Hence, $\pi^{*}=\pi_{T}^{*}=Y$.

\section{Proof of Proposition 4}

The plaintiff's overall success probability is

$$
\pi^{*}= \begin{cases}Y+\lambda\left(\pi_{T}^{*}-Y\right), & \text { in Scenario (i); } \\ \pi_{T}^{*}(\lambda+(1-\lambda) Y), & \text { in Scenario (ii); } \\ (1-\lambda) Y+\pi_{T}^{*}(1-(1-\lambda) Y), & \text { in Scenario (iii) }\end{cases}
$$

The derivative with respect to some parameter $\xi$ is:

$$
\frac{d \pi^{*}}{d \xi}=\frac{\partial \pi^{*}}{\partial \xi}+\frac{\partial \pi^{*}}{\partial \pi_{T}^{*}}\left(\frac{\partial \pi_{T}^{*}}{\partial \xi}+\frac{\partial \pi_{T}^{*}}{\partial S} \frac{\partial S}{\partial \xi}\right)
$$

Taking the derivative of (14) to obtain $\frac{\partial \pi_{T}^{*}}{\partial S}=-\pi_{T}^{*}\left(1-\pi_{T}^{*}\right) \frac{\tau}{S}$, and noting that $\alpha$ has no direct impact on $\pi_{T}^{*}$, we have

$$
\frac{d \pi^{*}}{d \alpha}= \begin{cases}-\lambda \pi_{T}^{*}\left(1-\pi_{T}^{*}\right) \frac{\tau}{S} \frac{\partial S}{\partial \alpha}, & \text { in Scenario (i); } \\ -(\lambda+(1-\lambda) Y) \pi_{T}^{*}\left(1-\pi_{T}^{*}\right) \frac{\tau}{S} \frac{\partial S}{\partial \alpha}, & \text { in Scenario (ii); } \\ -(1-(1-\lambda) Y) \pi_{T}^{*}\left(1-\pi_{T}^{*}\right) \frac{\tau}{S} \frac{\partial S}{\partial \alpha}, & \text { in Scenario (iii) }\end{cases}
$$

which proves the claim as $\frac{\partial S}{\partial \alpha}>(<) 0$ if and only if $Y<(>) 1 / 2$. More specifically, an increase in $\alpha$ increases $\pi^{*}-Y$ when the plaintiff is the favorite (i.e., when $Y>1 / 2$ ) and further decreases $\pi^{*}-Y$ when the defendant is the favorite (i.e., when $Y<1 / 2$ ). However, note that this is true only for local comparative statics, which don't move the case to another Scenario. Indeed, if $Y>1 / 2$ and the increase in $\alpha$ shifts the case from Scenario (iii) to Scenario (i), $\pi^{*}$ will unambiguously jump downwards as $\pi_{T}^{*}$ is, ceteris paribus, lower in Scenario (i) than in Scenario (iii), and $\pi^{*}$ is lower in Scenario (i) even for given $\pi_{T}^{*}$.

As for the comparative statics with respect to $\tau$, note first that $S$ does not depend on $\tau$. Again, we take the derivative of 14 to obtain $\frac{\partial \pi_{T}^{*}}{\partial \tau}=-\pi_{T}^{*}\left(1-\pi_{T}^{*}\right) \ln S$, which is 
positive if and only if $S<1$, which, in turn, is the case if and only if $Y>\frac{1}{2}$ (i.e., when the plaintiff is the favorite).

\section{E Proof of Proposition 5}

Using Proposition 1, we can substitute for the $V_{i}^{\ell}$ in $(22)$ to obtain

$$
\varepsilon= \begin{cases}2 \lambda \tau \pi_{T}^{*}\left(1-\pi_{T}^{*}\right)+2 \alpha(1-\lambda)\left[Y(1-(1-\lambda) Y)+\pi_{T}^{*} \lambda(1-2 Y)\right], & \text { in Scenario (i); } \\ 2 \pi_{T}^{*}(1-(1-\lambda)(1-Y))\left[\tau\left(1-\pi_{T}^{*}\right)+\alpha(1-\lambda)(1-Y)\right], & \text { in Scenario (ii); } \\ 2\left(1-\pi_{T}^{*}\right)(1-(1-\lambda) Y)\left[\tau \pi_{T}^{*}+\alpha(1-\lambda) Y\right], & \text { in Scenario (iii) }\end{cases}
$$

Part (a): If $\alpha=0$ (which may occur under any of the Scenarios (i)-(iii)), then $\pi_{T}^{*}=Y$, so that

$$
\varepsilon= \begin{cases}2 \lambda \tau Y(1-Y), & \text { in Scenario (i); } \\ 2 \tau Y(1-Y)(\lambda+(1-\lambda) Y), & \text { in Scenario (ii); } \\ 2 \tau Y(1-Y)(1-(1-\lambda) Y), & \text { in Scenario (iii). }\end{cases}
$$

all of which are smaller than $\varepsilon_{B}=2 \tau Y(1-Y)$.

To see the comparison of aggregate effort if $Y$ is close to 0 or 1 , note first that we are in Scenario (ii) if $Y$ approaches 0, and in Scenario (iii) if $Y$ approaches 1 unless we are in the limiting case in which $c_{A}=0$ which will be discussed below by reference to examples. Consider first the case where $Y$ approaches 0. As we are in Scenario (ii), we have

$$
\begin{aligned}
\varepsilon & =2 \pi_{T}^{*}(1-(1-\lambda)(1-Y))\left[\tau\left(1-\pi_{T}^{*}\right)+\alpha(1-\lambda)(1-Y)\right] \\
& <2 \pi_{T}^{*}\left(1-\pi_{T}^{*}\right)(1-(1-\lambda)(1-Y))[\tau+\alpha(1-\lambda)] \\
& <2 Y(1-Y)(1-(1-\lambda)(1-Y))[\tau+\alpha(1-\lambda)] \\
& <2 \tau Y(1-Y)
\end{aligned}
$$

if and only if $Y<\frac{\tau-\lambda \alpha}{\tau+(1-\lambda) \alpha}$. The first inequality is implied by $\pi_{T}^{*}<Y$ and the second by the fact that $\pi_{T}^{*}\left(1-\pi_{T}^{*}\right)<Y(1-Y)$ (which is true for all $\left.Y \in(0,1)\right)$. 
Similarly, if $Y$ approaches 1, so that we are in Scenario (iii) and $\pi_{T}^{*}>Y$, we have

$$
\begin{aligned}
\varepsilon & =2\left(1-\pi_{T}^{*}\right)(1-(1-\lambda) Y)\left[\tau \pi_{T}^{*}+\alpha(1-\lambda) Y\right] \\
& <2 \pi_{T}^{*}\left(1-\pi_{T}^{*}\right)(1-(1-\lambda) Y)[\tau+\alpha(1-\lambda)] \\
& <2 Y(1-Y)(1-(1-\lambda)(1-Y))[\tau+\alpha(1-\lambda)] \\
& <2 \tau Y(1-Y)
\end{aligned}
$$

if and only if $Y>\frac{\alpha}{\tau+(1-\lambda) \alpha}$.

There exist $Y$ that satisfy these sufficient conditions if and only if $\tau>\lambda \alpha$. The above refers to the scenarios in which $c_{A}$ is greater than zero. In the limiting case in which $c_{A}=0$, Scenario (i) from Proposition 1 will apply even when $Y \rightarrow 0$ or $Y \rightarrow 1$. The following examples show that $\varepsilon<\varepsilon_{B}$ also occurs in that scenario when $Y$ is sufficiently close to either 0 or 1 : If $\tau=\alpha=1, \varepsilon<\varepsilon_{B}$ when, for instance, $\lambda=1 / 4$ and either $Y<.21$ or $Y>.78, \lambda=1 / 2$ and either $Y<.19$ or $Y>.80$, and when $\lambda=3 / 4$ and either $Y<.17$ or $Y>.82$.

Parts $(b)-(d)$ : If $Y=1 / 2$, then Scenario (i) is relevant and $\pi_{T}^{*}=1 / 2$. Hence,

$$
\varepsilon=\lambda \frac{\tau}{2}+\frac{1-\lambda^{2}}{2} \alpha
$$

which is larger than $\varepsilon_{B}=\frac{\tau}{2}$ if and only if $\alpha>\frac{\tau}{1+\lambda}$, which is satisfied for all $\alpha \geq \tau$. Due to continuity, this is also true for a sufficiently small neighborhood of $Y=1 / 2$ (as claimed in Part (b)). Turning to Parts (c) and (d) in particular, note that we obtain $\frac{\partial \varepsilon}{\partial \alpha}>0$ and $\frac{\partial \varepsilon}{\partial \lambda}=\frac{\tau}{2}-\alpha \lambda>0$ if and only if $\alpha \lambda<\frac{\tau}{2}$.

\section{F Proof of Proposition 6}

We will discuss the scenarios of Proposition 1 one by one. Note that it is the underdog's expected payoff that is relevant for whether a case goes to trial, we will confine the following analysis to analyzing $\widehat{W}_{P}(Y)$ for $Y \leq 1 / 2$ and $\widehat{W}_{D}(Y)$ for $Y>1 / 2$ :

Scenario (i): Assume first that $Y \leq \frac{1}{2}$, so that the case goes to trial if and only if 


$$
\widehat{W}_{P}(Y)>0
$$

$$
\begin{aligned}
\widehat{W}_{P}(Y)=\lambda \pi_{T}^{*}(1 & \left.-\tau\left(1-\pi_{T}^{*}\right)\right)+(1-\lambda) Y(1-\alpha(1-Y)) \\
& -\alpha \lambda(1-\lambda)\left[(1-2 Y) \pi_{T}^{*}\left(1-\tau\left(1-\pi_{T}^{*}\right)\right)+Y^{2}\right]-c_{A}-c_{T},
\end{aligned}
$$

which is decreasing in $\alpha$ as both the partial derivative with respect to $\alpha$ and the indirect effect via $\pi_{T}^{*}$ are negative $\left(\partial \widehat{W}_{P}(Y) / \partial \pi_{T}^{*}>0, \partial \pi_{T}^{*} / \partial S<0\right.$ and $\partial S / \partial \alpha>0$ if $Y<$ $1 / 2)$. Furthermore, $\widehat{W}_{P}(Y)$ is smaller than the expected gross payoff in the single-stage benchmark $Y(1-\tau(1-Y))-c$ for $\alpha=\tau$ as $Y \leq 1 / 2$ and, thus, $\pi_{T}^{*} \leq Y$. For $\alpha=0$, $\widehat{W}_{P}(Y)=Y(1-\lambda \tau(1-Y))-c>Y(1-\tau(1-Y))-c$ since $\lambda \in(0,1)$.

If $Y>\frac{1}{2}$, the case goes to trial if and only if $\widehat{W}_{D}(Y)>-1$, which is shown in Proposition 2 to be equivalent to $\widehat{W}_{P}(1-Y)>0$, so that the above analysis applies as $1-Y<\frac{1}{2}$

Scenario (ii): In this case, $Y \leq \frac{1}{2}$, so that the case goes to trial if and only if $\widehat{W}_{P}(Y)>0$ :

$$
\widehat{W}_{P}(Y)=\pi_{T}^{*}\left(1-\tau\left(1-\pi_{T}^{*}\right)\right)\left\{[1-(1-\lambda)(1-Y)][1-\alpha(1-\lambda)(1-Y)]-c_{A}\right\}-c_{T}
$$

which is decreasing in $\alpha$ (again, both direct and indirect effects are negative) and smaller than $Y(1-\tau(1-Y))-c$ for $\alpha=\tau$ as $Y \leq 1 / 2$ and, thus, $\pi_{T}^{*} \leq Y$. For $\alpha=0$, $\widehat{W}_{P}(Y)=Y(1-\tau(1-Y))\left[1-(1-\lambda)(1-Y)-c_{A}\right]-c_{T}$, which (recalling that we are requiring $c=c_{T}+\pi_{T}^{*} c_{A}$ in this scenario) can be smaller or larger than $Y(1-\tau(1-Y))-c$ depending on how $c$ is allocated between $c_{T}$ and $c_{A}$ in the two-stage system. Recalling that $\widehat{W}_{P}(Y)$ is continuous at the boundary between Scenarios (i) and (ii) as $V_{P}^{0}$ is continuous completes the proof of Part (c).

Scenario (iii): As $Y>\frac{1}{2}$ in this scenario, the case goes to trial if and only if $\widehat{W}_{D}(Y)>$ -1 , which is shown in Proposition 2 to be equivalent to $\widehat{W}_{P}(1-Y)>0$, so that the analysis of Scenario (ii) applies as $1-Y<\frac{1}{2}$.

Scenario (iv): In this scenario, no case reaches the trial court. By contrast, a case in a single-stage system would go to trial if and only if $Y(1-\tau(1-Y))-c \geq 0$. As there is no case that goes to trial in a two-stage system but would do so in a single-stage system, this certainly is true whenever $\alpha \geq \tau$, thus proving Part (a). Part (b) is only concerned 
with Scenario (i), so that it is irrelevant here. Finally, the result that the case does not go to trial is independent of $\alpha$, thus proving part (c).

Scenario $(v)$ : As cases in this scenario do not go to the appeals court, the decision of whether to go to trial is identical to that in a single-stage system, so that parts (a) and (c) of the proposition follow immediately, and part (b) does not apply as it is only concerned with Scenario (i).

\section{References}

ACAS (2015): Discipline and Grievances at Work. http://www.acas.org.uk.

BAIK, K. H., AND I.-G. Kim (2007a): "Contingent fees versus legal expenses insurance," International Review of Law and Economics, 27(3), 351-361.

(2007b): "Strategic Decisions on Lawyers Compensation in Civil Disputes," Economic Inquiry, 45(4), 854-863.

Bassett, D. L. (2002): "I Lost at Trial-In the Court of Appeals!: The Expanding Power of the Federal Appellate Courts to Reexamine Facts," Houston Law Review, 38, 1129-1194.

Bernardo, A. E., E. Talley, and I. Welch (2000): "A theory of legal presumptions," Journal of Law, Economics, and Organization, 16(1), 1-49.

CEPEJ (2014): Report on 'European judicial systems - Edition 2014 (2012 data): efficiency and quality of justice'. http://www.coe.int.

Chen, K.-P., And J.-S. WAng (2007): "Fee-shifting rules in litigation with contingency fees," Journal of Law, Economics, and Organization, 23(3), 519-546.

Clermont, K. M., And T. Eisenberg (2001): "Appeal from jury or judge trial: defendants' advantage," American Law and Economics Review, 3(1), 125-164.

(2002): "Litigation realities," Cornell Law Review, 88, 119-154. 
DAughety, A., And J. Reinganum (2000a): "Appealing Judgments," RAND Journal of Economics, 31(3), 502-525.

(2000b): "On the economics of trials: adversarial process, evidence, and equilibrium bias," Journal of Law, Economics, and Organization, 16(2), 365-394.

Demougin, D., And C. Fluet (2006): "Preponderance of evidence," European Economic Review, 50(4), 963-976.

Denter, P., And D. SisaK (2015): "Do polls create momentum in political competition?," Journal of Public Economics, 130, 1-14.

Dixit, A. (1987): "Strategic behavior in contests," American Economic Review, pp. 891-898.

Eisenberg, T., And M. Heise (2009): "Plaintiphobia in State Courts? An Empirical Study of State Court Trials on Appeal," Journal of Legal Studies, 38(1), 121-155.

(2015): "Plaintiphobia in State Courts Redux? An Empirical Study of State Court Trials on Appeal," Journal of Empirical Legal Studies, 12(1), 100-127.

FArmer, A., And P. PeCorino (1999): "Legal expenditure as a rent-seeking game," Public Choice, 100(3-4), 271-288.

(2016): Liability Standards with an Uncertain Outcome at Trial. mimeo.

Garner, B. A. (2011): Garner's Dictionary of Legal Usage. Oxford University Press.

GÜrtler, O., ANd M. KrÄKel (2010): "Double-Sided Moral Hazard, Efficiency Wages, and Litigation," Journal of Law, Economics, and Organization, 26(2), 337-364.

Hirshleifer, J., And E. Osborne (2001): "Truth, effort, and the legal battle," Public Choice, 108(1-2), 169-195. 
Iossa, E., And G. Palumbo (2007): "Information Provision and Monitoring of the Decision-Maker in the Presence of an Appeal Process," Journal of Institutional and Theoretical Economics, 163(4), 657-682.

KATz, A. (1988): "Judicial decisionmaking and litigation expenditure," International Review of Law and Economics, 8(2), 127-143.

Klumpp, T., And M. K. Polborn (2006): "Primaries and the New Hampshire effect," Journal of Public Economics, 90(6), 1073-1114.

Konrad, K. (2009): Strategy and Dynamics in Contests. Oxford University Press.

Konrad, K. A., And D. Kovenock (2009): "Multi-battle contests," Games and Economic Behavior, 66(1), 256-274.

Landeo, C., And M. Nikitin (2018): "Financially-Constrained Lawyers: An Economic Theory of Legal Disputes," Games and Economic Behavior, 109, 625-647.

Levy, G. (2005): "Careerist Judges and the Appeals Process," RAND Journal of Economics, 36(2), 275-297.

Luppi, B., AND F. PARIsi (2012): "Litigation and legal evolution: does procedure matter?," Public Choice, 152(1-2), 181-201.

Münster, J. (2009): "Repeated contests with asymmetric information," Journal of Public Economic Theory, 11(1), 89-118.

Nalebuff, B. (1987): "Credible Pretrial Negotiation," RAND Journal of Economics, 18(2), 198-210.

PARISI, F. (2002): "Rent-seeking through litigation: adversarial and inquisitorial systems compared," International Review of Law and Economics, 22(2), 193-216.

PowELl, R. (2007): "Allocating defensive resources with private information about vulnerability," American Political Science Review, 101(04), 799-809. 
Shavell, S. (1985): "Uncertainty over Causation and the Determination of Civil Liability," The Journal of Law \& Economics, 28(3), 587-609.

(1995): "The Appeals Process as a Means of Error Correction," Journal of Legal Studies, 24(2), 379-426.

(2006): "The Appeals Process and Adjudicator Incentives," Journal of Legal Studies, 35, 1-475.

(2007): "Optimal Discretion in the Application of Rules," American Law and Economics Review, 9(1), 175-194.

(2010): "On the Design of the Appeals Process: The Optimal Use of Discretionary Review Versus Direct Appeal," Journal of Legal Studies, 39(1), 63-108.

Slantchev, B. L. (2010): "Feigning weakness," International Organization, 64(03), $357-388$.

Spitzer, M., And E. Talley (2000): "Judicial Auditing," The Journal of Legal Studies, $29(2), 649-683$.

Tullock, G. (1980): "Efficient Rent Seeking," in Toward a Theory of the Rent-Seeking Society, ed. by J. M. Buchanan, R. D. Tollison, and G. Tullock, pp. 269-282. Texas A\&M University Press.

WÄRNERYD, K. (2000): "In defense of lawyers: moral hazard as an aid to cooperation," Games and Economic Behavior, 33(1), 145-158.

Wohlschlegel, A. (2014): The Appeals Process and Incentives to Settle. MPRA Working Paper 59424.

YILDIRIM, H. (2005): "Contests with multiple rounds," Games and Economic Behavior, 51(1), 213-227. 